\title{
Metal Silicate Mixtures: Spectral Properties and Applications to Asteroid Taxonomy
}

\author{
EDWARD A. CLOUTIS \\ Department of Geology, University of Alberta, Edmonton, Canada \\ Michael J. Gaffey \\ Department of Geology, Rensselaer Polytechnic Institute, Troy, New York \\ DORIAN G. W. SMITH AND RICHARD ST J. LAMBERT \\ Department of Geology, University of Alberta, Edmonton, Canada
}

\begin{abstract}
The reflectance spectra of combinations of olivine, orthopyroxene, and iron meteorite metal show systematic variations in spectral properties which can be used to constrain many of the physical and chemical properties of the assemblages. The presence of metal most noticeably affects band area ratios, peak:peak and peak:minimum reflectance ratios, and band widths. These parameters are also affected to varying degrees by thè abundance and grain size of the metal and silicates and the composition of the silicates. Band width and band areas are useful for determining metal abundance in olivine + metal and orthopyroxene + metal assemblages, respectively. Mafic silicate grain size variations are best determined using band depth criteria. Band centers are most useful for determining mafic silicate composition. Analysis of the reflectance spectrum of the S-class asteroid (8) Flora on the basis of these spectral parameters indicates a surface composed of approximately 50 wt $\%$ metal, 40 wt $\%$ olivine $(\mathrm{Fa}=35 \pm 10), 10 \mathrm{wt} \%$ orthopyroxene ( $\mathrm{Fs}=30 \pm 25$ ), and perhaps a few weight percent of clinopyroxene. A substantial amount of the surface seems to consist of a fine-grained $(<45 \mu \mathrm{m}$ size) component. Analysis of the reflectance spectrum of the A-class asteroid (446) Aeternitas

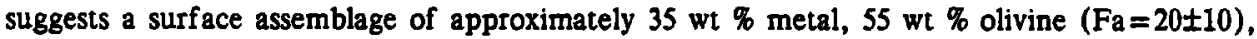
$7 \mathrm{wt} \%$ clinopyroxene (Fs $<17 \%$ ), and $3 \mathrm{wt} \%$ orthopyroxene (Fs $<45$ ). A substantial fine-grained ( $<45 \mu \mathrm{m}$ size) surface component is also indicated for this asteroid.
\end{abstract}

\section{INTRODUCTION}

Remote sensing is one of the most effective means for deriving information about the surface compositions of terrestrial and extraterrestrial targets which are inaccessible to direct sampling. Consequently, it is imperative that the maximum amount of compositional information be derived from such studies. Reflectance spectroscopy is one of the most ef fective tools in remote sensing, and in order to improve the quality and quantity of information derivable from spectral studies, the spectral reflectance properties of mafic silicate-meteoritic metal mixtures have been examined.

These particular assemblages were chosen because accurate, quantitative identification and analysis of these materials have potentially important implications for theories concerning the origin and evolution of the asteroid belt [Gaffey, 1984, 1986] and perhaps the solar system [Bell, 1986; Gaffey, 1988]. The $S$-class asteroids are the most abundant group in the inner part of the main asteroid belt [Gradie and Tedesco, 1982]. Their mineralogy, particularly the nature of the metallic phase, is disputed. These objects have been interpreted as being either

Copyright 1990 by the American Geophysical Union.

Paper number 89JB03409. 0148-0227/90/89JB-03409\$05.00 differentiated objects with affinities to certain "primitive" achondrites [Gaffey, 1984, 1986; Bell and Kell, 1987] or parent bodies for the ordinary chondrites and hence undifferentiated [Anders, 1978; Feterberg et al., 1982]. The competing interpretations are almost exclusively based on differing interpretations of the telescopic spectral data. Important constraints can be placed on early solar system history depending on which interpretation ultimately proves to be correct.

The recent identification of probable olivine- and metal-rich asteroids also hinges on correct interpretation of the telescopic spectra [Bell et al., 1984a,b; Cruikshank and Hartmann, 1984]. If these $A$-class asteroids are differentiated objects, then they are most likely the remnants of once larger planetesimals whose outer layers have been stripped away by impacts to reveal their core-mantle boundaries, and they are mineralogically similar to pallasite meteorites [Buseck, 1977; Bell et al., 1984b]. The necessary laboratory spectral studies were undertaken in order to constrain the possible surface mineralogies of these important classes of asteroids.

The spectral reflectance properties of the individual end member phases (olivine, orthopyroxene, and metal) and olivine-orthopyroxene mixtures have been extensively studied. Olivine reflectance spectra in the 0.3-2.6 $\mu \mathrm{m}$ wavelength region show a broad asymmetric absorption feature near $1 \mu \mathrm{m}$, which is composed of three overlapping absotption bands 
[Burns, 1970a; Roush, 1984]. These bands arise from electronic transitions in $\mathrm{Fe}^{2+}$ cations located in two distinct crystallographic sites. The band minimum progressively shif ts toward longer wavelengths with increasing iron content, and its wavelength position can be used to determine iron content [Cloutts, 1985; King and Ridley, 1987]. The only other resolvable, pervasive absorption band is a weak feature situated near $0.65 \mathrm{\mu m}$ whose origin is still unclear [Burns, 1970a; Mao and Bell, 1972; Burns et al., 1973; Runciman et al., 1973; Hazen et al., 1977; Roush, 1984], but it seems to be useful for further constraining olivine composition [King and Ridley, 1987]. A steep drop-off in reflectance occurs at wavelengths shorter than $0.55 \mu \mathrm{m}$ due to various charge transfer absorptions but does not appear to be diagnostic of any particular composition [Burns, 1970a; Burns et al., 1972].

Low-calcium pyroxene, which will be referred to here as orthopyroxene (OPX), exhibits two main absorption bands in its reflectance spectrum near $1 \mu \mathrm{m}$ and $2 \mu \mathrm{m}$ (bands I and II, respectively). These features are due to crystal field transitions in ferrous iron located in the M2 crystallographic site [Clark, 1957; White and Keester, 1967; Burns, 1970b; Burns et al., 1972; Roush, 1984]. As with olivine, the wavelength positions of these bands shift to longer wavelengths with increasing iron content [Adams and McCord, 1972; Adams, 1974; Cloutis, 1985; Cloutls et al., 1986a,b]. The presence of the band at 2 $\mu \mathrm{m}$ is useful for easily distinguishing pyroxene from olivine.

A number of meteoritic metals and nickel-iron alloys have been spectrally characterized. In almost all cases the various $\mathrm{Ni}-\mathrm{Fe}$ alloys show a featureless spectrum between 0.3 and 2.7 $\mu \mathrm{m}$ with a gradual rise in reflectance toward longer wavelengths (red slope). The spectral slope is dependent on the particle size or surface roughness of the metal and, to a lesser extent, on its chemistry [Watson, 1938; Yolken and Kruger, 1965; Blodgett and Spicer, 1967; Gorban et al., 1973; Johnson and Fanale, 1973; Gorban and Stashchuk, 1974; Gaffey, 1976; Dollfus et al., 1980; Feterberg et al., 1982; McFadden, 1983; Wagner et al., 1987; Britt and Pleters, 1988; Cloutls et al., 1990].

The evidence for comminuted materials on the surfaces of metal-rich asteroids is compelling. Meteorites which presumably resided for a period of time at the surfaces of their parent bodies (solar gas-rich breccias) show comminuted textures [Wilkening, 1983; Williams et al., 1984, 1986; Bell and Kell, 1987; Britt and Pieters, 1987]. The available photopolarimetric data for most S-class asteroids are best modelled as a particulate surface layer [Veverka, 1971; Zellner et al., 1977; Barucci et al., 1984] probably composed largely of $-100-\mu \mathrm{m}$-sized grains [Dollfus and Zellner, 1979]. Thermal radiometric models of the larger asteroids tend to support the polarimetric results for a comminuted surface [Morrison and Lebofsky, 1979], and metal-rich surfaces on S-class asteroids [Gaffey, 1989]. Radar albedos of main belt S-class asteroids, assuming a certain metallic component, seem to indicate particulate regoliths with approxımately lunar porosities [Ostro et al., 1985]. Computational models of asteroid evolution favor the development of a substantial surface regolith on all but the smallest asteroids [Comerford, 1967; Cintala et al., 1979; Housen et al., 1979a,b; Housen and Wilkening, 1982; King et $a l ., 1984]$. The reflectance spectra of three A-class asteroids are best simulated by fine-grained olivine scattered on a roughened metal substrate. Large olivine grains, such as those found in pallasites, do not match the spectral data and must be extensively fragmented to provide the necessary match [Bell et al., 1984a].

At the temperatures present in the main asteroid belt, kamacite lies in the brittle-ductile transition region and may be subject to brittle deformation during impacts [Zukes, 1969; Auten, 1973; Remo and Johnson, 1975]. Laboratory impact studies of meteoritic metal show the development of irregular surfaces and the comminution of the metal even at room temperatures [Auten, 1973; Marcus and Hackett, 1974; Matsul and Schultz, 1984]. Comminution of differentiated metal may also be facilitated by the presence of exsolved and included phases such as schreibersite/rhabdite, troilite, graphite, and cohenite. These phases could serve as areas of weakness in the metal and facilitate fracturing [Baldanza and Pialla, 1969; Comerford, 1969; Doan and Goldstein, 1969].

\section{EXPERIMENTAL PROCEDURE}

Natural and synthetic materials were used in this study. The olivine (OLV003) was separated from large pale green grains from San Carlos, Arizona. The pyroxenes (PYX032, PYX117) are from Ekersund, Norway, and an unspecified locality in India, respectively. Powders were obtained from a single, partial crystal in both cases. The metal (MET101) was ground from a fresh, interior sample of the Odessa, Texas, coarse octahedrite [Buchwald, 1975].

Chemical analyses of the samples were acquired at the University of Calgary SEMQ microprobe facility and represent an average of six or more point analyses or area scans (Table 1). The ferrous iron values of the silicates were obtained by wet chemistry, and ferric iron was calculated from the difference between total and ferrous iron. For the meteoritic metal, only the kamacite phase, which forms the bulk of the sample [Buchwald, 1975], was analyzed.

Mafic silicate powders were obtained by crushing in an alumina mortar and pestle. Impurities were removed by a combination of magnetic separation and hand picking. The cleaned samples were repeatedly wet sieved with acetone to ensure well-constrained size fractions. The 0.45 and $45.90 \mu \mathrm{m}$ size ranges were used in the various mixtures. The metal powder was produced by grinding a portion of an alteration-free piece of the iron meteorite on an emery

TABLE 1. Chemical Composition of the Minerals Used in This Study

\begin{tabular}{|c|c|c|c|c|c|}
\hline & OLV003 & PYX032 & PYX117 & Element & MET101 \\
\hline $\begin{array}{l}\mathrm{SiO}_{2} \\
\mathrm{FeO} \\
\mathrm{Fe}_{2} \mathrm{O}_{3} \\
\mathrm{MgO} \\
\mathrm{CaO} \\
\mathrm{Al}_{2} \mathrm{O}_{3} \\
\mathrm{NiO} \\
\mathrm{TiO}_{2} \\
\mathrm{MnO} \\
\mathrm{Cr}_{2} \mathrm{O}_{3} \\
\mathrm{Na}_{2} \mathrm{O} \\
\mathrm{ZnO} \mathrm{CoO} \\
\mathrm{V}_{2} \mathrm{O}_{5} \\
\mathrm{~K}_{2} \mathrm{O} \\
\mathrm{ZrO}_{2}\end{array}$ & $\begin{array}{r}40.64 \\
9.25 \\
0.59 \\
49.13 \\
0.07 \\
<0.01 \\
0.33 \\
0.00 \\
0.09 \\
0.01 \\
0.00 \\
0.00 \\
0.04 \\
0.00 \\
0.00 \\
\text { N.D. }\end{array}$ & $\begin{array}{r}50.21 \\
23.65 \\
5.11 \\
17.57 \\
1.59 \\
1.24 \\
0.01 \\
0.19 \\
0.53 \\
0.04 \\
0.00 \\
\text { N.D. } \\
0.06 \\
<0.01 \\
\text { N.D. } \\
0.00\end{array}$ & $\begin{array}{r}53.54 \\
16.17 \\
1.02 \\
27.53 \\
0.35 \\
1.54 \\
0.05 \\
0.03 \\
0.44 \\
0.07 \\
0.00 \\
\text { N.D. } \\
0.01 \\
0.00 \\
\text { N.D. } \\
0.00\end{array}$ & \begin{tabular}{r}
$\mathrm{Si}$ \\
$\mathrm{Fe}$ \\
\hdashline- \\
$\mathrm{Mg}$ \\
$\mathrm{Ca}$ \\
$\mathrm{Al}$ \\
$\mathrm{Ni}$ \\
$\mathrm{Ti}$ \\
$\mathrm{Mn}$ \\
$\mathrm{Cr}$ \\
$\mathrm{Na}$ \\
$\mathrm{Zn}$ \\
$\mathrm{Co}$ \\
$\mathrm{V}$ \\
$\mathrm{K}$ \\
$\mathrm{ZI}$ \\
$\mathrm{S}$ \\
$\mathbf{P}$ \\
$\mathrm{Cu}$ \\
$\mathrm{Pb}$ \\
.-
\end{tabular} & $\begin{array}{r}\text { N.D. } \\
93.39 \\
0 . \\
0.00 \\
\text { N.D. } \\
0.03 \\
6.07 \\
0.00 \\
0.00 \\
0.18 \\
0.00 \\
0.11 \\
0.50 \\
0.00 \\
\text { N.D. } \\
\text { N.D. } \\
0.00 \\
0.02 \\
0.00 \\
0.87 \\
101.17\end{array}$ \\
\hline
\end{tabular}

Values are in weight percent. 
grinder, magnetically separated from the grinding wheel contaminants, and repeatedly wet sieved with acetone. A portion of the metal powder was beaten in the mortar to reduce the metal shavings to a more equidimensional habit and wet sieved with acetone to the various size fractions. The 45-90 $\mu \mathrm{m}$ portion of this material was used in the olivine-metal mixtures. Immediately upon completion of the sieving, the samples were transferred to a dry nitrogen environment for storage. They were briefly removed for incorporation into the mineral mixtures, and returned to the nitrogen environment. In total, the metal powders were exposed to normal atmosphere for a maximum of 5 days. The various mineral mixtures were made on a weight percent basis with an accuracy of $\pm 0.1 \%$. The olivine-metal (OLV003-MET101), and one of the pyroxene-metal mixtures (PYX117-MET101) were made at $25 \mathrm{wt} \%$ intervals, and the other pyroxene-metal mixture (PYX032MET101) at $50 \mathrm{wt} \%$ intervals. In addition, a 30:40:30 mixture of OLV003:PYX117:MET101, and its metal-free equivalent (OLV003:PYX117=43:57) were also prepared.

The reflectance spectra were acquired at the NASA RELAB spectrometer facility at Brown University, and at the U.S. Geological Survey spectrometer facility in Denver, Colorado. Details of the respective instruments are given by Pleters [1983] and King and Ridley [1987]. The samples measured at the RELAB facility (OLV003-MET101 series, OLV003:PYX117, OLV003:PYX117:MET101, and the various end-members) were acquired at an incidence angle of $0^{\circ}$ and an emission angle of $15^{\circ}$. The PYX-MET mixtures and end-members were measured at the U.S. Geological Survey facility using an integrating sphere arrangement. All the spectra were measured relative to halon, a near-perfect diffuse reflector in the wavelength region of interest (0.3-2.7 $\mathrm{\mu m}$ [Weidner and Hsia, 1981]), corrected for minor $(-2 \%)$ irregularities in halon's absolute reflectance in the $2-\mu \mathrm{m}$ region, as well as for dark current offsets. The reflectance spectra were processed and analyzed using the Gaffey Spectral Processing System, a PC-compatible version of SPECPR [Clark, 1980]. Continuum removal was performed by dividing out a straight-line tangent to the reflectance spectrum on either side of an absorption band. Band centers and band minima were calculated by fitting a quadratic equation to -10 data points on either side of a visually determined minimum or center.

\section{RESULTS}

The various spectra have been divided up into three groupsOLV+MET and end-members, PYX+MET and end-members, and $O L V+P Y X+M E T$ and $O L V+P Y X$ and end-members. Each group possesses distinct spectral properties which can be used to identify the particular minerals present in the assemblages and to constrain some of their physical and chemical properties.

\section{Ollyine-Metal Mixtures}

Very little spectral data exist for olivine-metal mixtures. Gaffey [1976] in his comprehensive examination of meteorite spectra did not include pallasites (olivine-metal meteorites) because of the difficulties in sample preparation. Bell et al. [1984a] measured the reflectance spectra of olivine grains scattered on a roughened metal background and concluded that fine-grained olivine + metal substrate provides the best match to the telescopic data for A-class asteroids, although the overall red slope due to the metal could not be accurately reproduced. Gaffey [1986] cites an unpublished study of very fine grained iron $(3 \mu \mathrm{m})$ mixed with two sizes of olivine $(<45 \mu \mathrm{m}$ and 125-250 $\mu \mathrm{m})$. The very fine grained iron imparted a red slope to the spectra.

Intimate mixtures of olivine and metal involve the interaction of a mineral with a broad absorption band near 1 $\mu \mathrm{m}$ and a relatively flat reflectance slope beyond $1.8 \mu \mathrm{m}$ (olivine), with a material having a featureless, red slope of low overall reflectance (metal). The various olivine-metal mixtures using the $45.90 \mu \mathrm{m}$ sized olivine and the $45.90 \mu \mathrm{m}$ sized beaten metal are shown in Figure 1. These mixtures are all characterized by a variable strength absorption band near $1 \mu \mathrm{m}$ (band I) and no band near $2 \mu \mathrm{m}$ (band II). This is used as an initial criterion for determining whether an olivine-rich

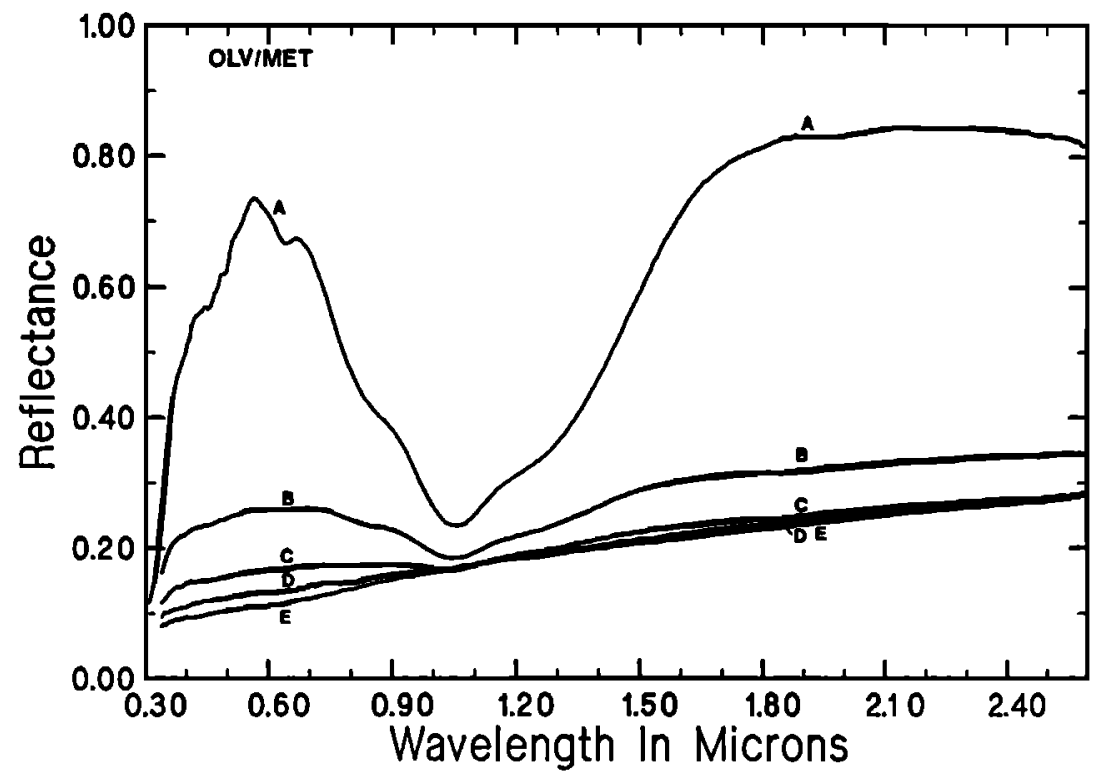

Fig. 1. Absolute reflectance spectra $(0.3-2.6 \mu \mathrm{m})$ of the 45-90 $\mu \mathrm{m}$ sized olivine + meteoritic metal mixtures. The numbers given for each spectrum indicate the olivine and metal weight percentages, respectively (e.g., 75 wt \% olivine plus $25 \mathrm{wt} \%$ metal is indicated as $75 / 25$ ). Spectrum $A=100 / 0$, spectrum $B=75 / 25$, spectrum $C=50 / 50$, spectrum $D=25 / 75$, spectrum $E=0 / 100$. 
assemblage is present and amenable to the spectral deconvolution procedures developed for OLV-MET mixtures.

A large number of olivine spectra are available in the literature, and many of these were included in the search for spectral systematics [Adams, 1975; Hunt and Evarts, 1981; Mlyamoto et al., 1981; Singer, 1981; Mi yamoto et al., 1983; Cloutls, 1985; King and Ridley, 1987; Pieters and Mustard, 1988]. Progressively increasing amounts of metal added to olivine alter the mafic silicate spectrum in systematic ways. In naturally occurring olivines, the reflectance from 1.8 to $2.5 \mu \mathrm{m}$ is essentially constant, with the exception of some iron-rich members [Cloutis, 1989]. Metal is substantially redder in this wavelength region, even for the most finely powdered sample $(0-45 \mu \mathrm{m})$. A red slope seems to be characteristic of all nickel-iron alloys with a grain size or surface roughness greater than the wavelength of light [e.g., Gaffey, 1986; Miyamoto, 1987; Britt and Pieters, 1988]. OLV-MET spectra fall somewhere between these two extremes and the $2.5 / 1.8 \mu \mathrm{m}$ reflectance ratio can be used to determine the metal abundance. A fourfold increase in metal grain size would alter the estimate of metal abundance by only $10 \%$. Unfortunately, this calibration is valid only for pyroxene-free samples, as the addition of even a few percent pyroxene dramatically reduces this reflectance ratio.

A more widely applicable calibration involves the width of band I. Increasing amounts of metal impart a red slope to the olivine, this effect being more pronounced at shorter wavelengths. The width of band $I$ is measured by the intersection of a horizontal straight line continuum tangent to the local reflectance maximum between $\sim 0.5$ and $0.7 \mu \mathrm{m}$ with the long-wavelength side of band $I$. The intersection point of this tangent for all olivines, regardless of particle size and chemistry, falls between 1.45 and $1.62 \mu \mathrm{m}$. The addition of even $25 \mathrm{wt} \%$ metal snif ts the intersection point to a value well below the olivine field (Figure 2). Extrapolating from pure metal spectra [Cloutis et al., 1990], a fourfold increase in metal grain size would result in overestimating metal abundance by $-10 \%$. At this point no acceptable spectral criterion has been found for determining the grain size of the metal, except for the $2.5 / 1.8 \mu \mathrm{m}$ reflectance ratio. The intersection point criterion is much less sensitive to small amounts of pyroxene than the $2.5 / 1.8 \mu \mathrm{m}$ ratio.

The depth of the major ferrous iron olivine absorption band (band I) measured as the reflectance ratio at $1.8 \mu \mathrm{m}$ divided by the reflectance at the band minimum increases as olivine grain size increases. Reflectance ratios are pariicularly useful parameters because they are dimensionless and are independent of absolute reflectance, which is unavailable in many cases. The $1.8 \mu \mathrm{m} /$ band I minimum reflectance ratio increases with increasing grain size to a maximum of -10 , at which point the absorption band becomes saturated. This ratio is severely depressed by the addition of metal and appears to be relatively independent of metal grain size (Figure 3). Since the abundance of metal has been determined from the intersection point critericn, correcting for metal abundance will yield the olivine grain size. A series of contours can be constructed on Figure 3 connecting points of equal metal abundance. These contours are not shown because the necessary samples have not yet been characterized. The reflectance ratio for an unknown spectrum platted in Figure 3 for a given metal content will yield the olivine grain size.

The final factor which can be determined is the ferrous iron content of the olivine. In pure olivines, the wavelength position of the band minimum and band center shifts to longer

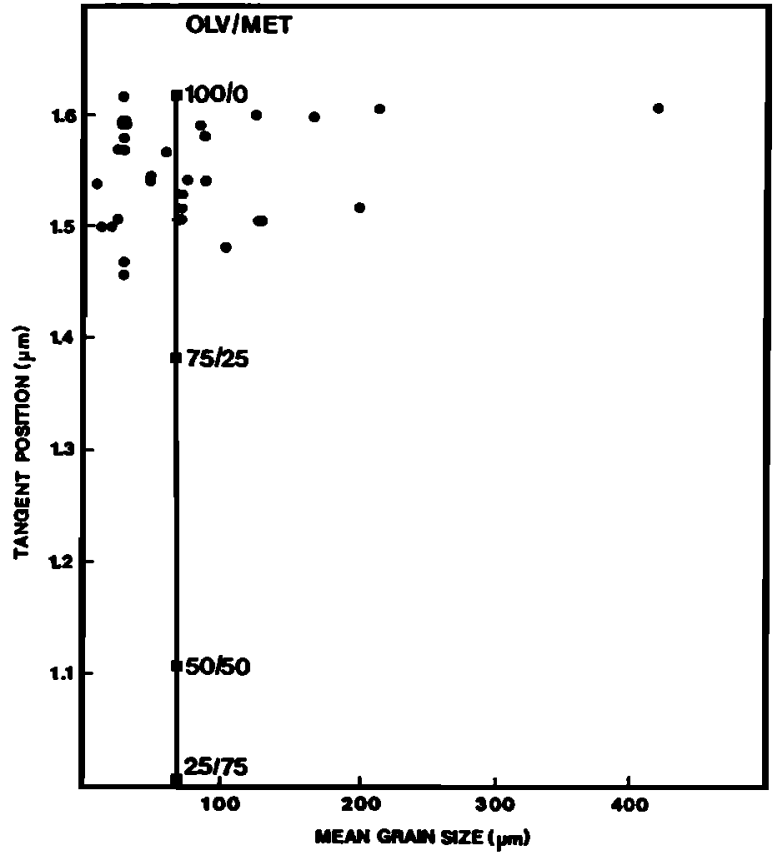

Fig. 2. Wavelength positions of the intersection of a horizontal continuum tangent to the local reflectance maximum near $0.5-0.7 \mu \mathrm{m}$ with the long-wavelength wing of the major absorption band (band $\mathrm{I}$ ) as a function of mean grain size. See text for a more complete explanation of the tangent. Squares indicate the data for the olvine+metal spectra of Figure 1. The olivine/metal abundances are indicated in the same way as for Figure 1.

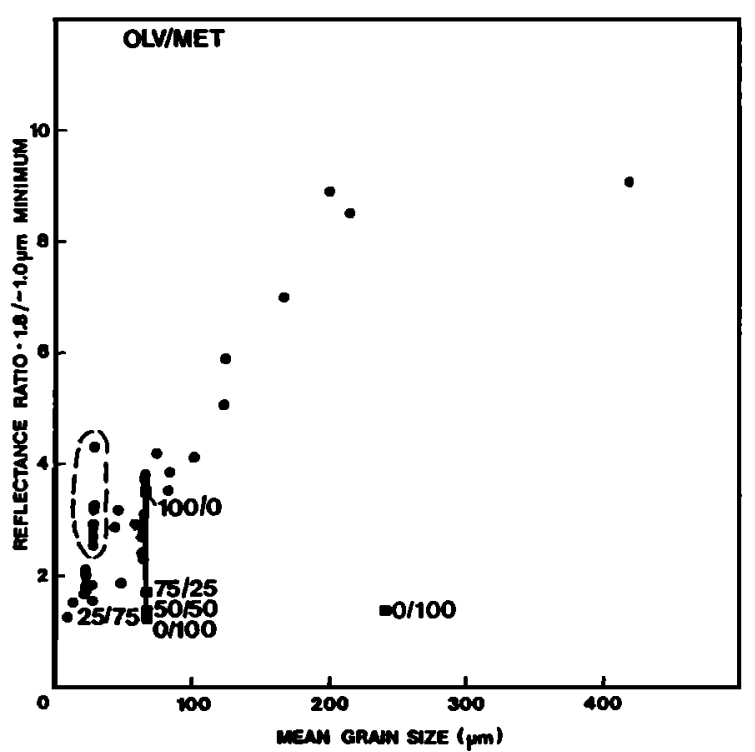

Fig. 3. Ratio of the absolute reflectance at $1.8 \mu \mathrm{m}$ to the reflectance of the band I minimum near $1 \mu \mathrm{m}$, as a function of mean grain size. The points surrounded by the dashed line are some iron-rich olivines which fall of the general trend. Symbols are the same as in Figure 2. The isolated square labelled $0 / 100$ is the $1.8 / 1.0 \mathrm{\mu m}$ reflectance ratio of a larger grain size metal. The addition of metal reduces this reflectance ratio, while increasing olivine grain size correlates with an increase in the reflectance ratio. Olivine/metal abundances are indicated in the same way as for Figure 1. 
wavelengths with increasing iron content from -1.05 to $1.09 \mu \mathrm{m}$ (Figure 4). The presence of metal causes an apparent shift of the band minimum towards shorter wavelengths. In the mixtures studied, $50 \mathrm{wt} \%$ metal shifts the band minimum and band center downward by 21 and $6 \mathrm{~nm}$, respectively. Extrapolating from the spectra of various sized metal powders, a fourfold increase in metal grain size would accelerate the shift in band center by only 1-2 $\mathrm{nm}$. The iron content of the olivine can be determined by adding a value to the band rninimum or band center equivalent to the amount of metal present, since a straight-line continuum is not a completely satisfactory correction for the metal. Failure to correct fully for this discrepancy will provide only the minimum iron content of the olivine.

\section{Pyroxene-Metal Mixtures}

Pyroxene- and metal-rich meteorites include lodranites, mesosiderites, siderophyres, and winonaites [Mason, 1962; Powell, 1969, 1971; Mason and Jarosewich, 1973; Prinz et al., 1980; King et al., 1981; Mort et al., 1984]. To date there has been very little success in identifying possible parent bodies for these meteorites on the basis of telescopic spectral studies. The pyroxene-metal spectral data may help to overcome this difficulty and perhaps provide additional information on unsampled asteroid types.

The available spectral data for pyroxene-metal (PYX-MET) mixtures is of variable quality. Gaffey [1976] examined the reflectance spectrum of one mesosiderite (Veramin) which showed two weak absorption bands at the approximate positions expected for pyroxene. A number of enstatite chondrites,

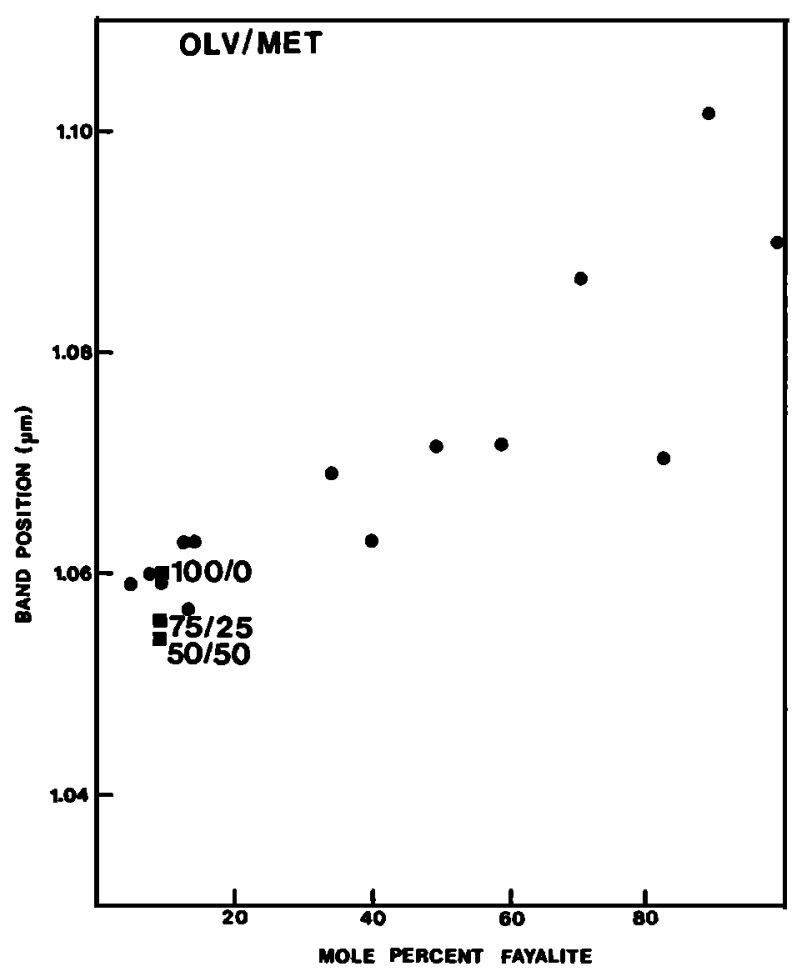

Fig. 4. Wavelength position of the band 1 centers, after division of a straight-line continuum, as a function of olivine iron content. Symbols are the same as in Figure 2. Olivine/metal abundances are indicated in the same way as in Figure 1. containing metal and nearly pure iron-free enstatite, were also examined. These meteorites show almost no $\mathrm{Fe}^{2+}$ absorption bands [Gaffey, 1976; Miyamoto, 1987] because the pyroxene is almost pure $\mathrm{MgSiO}$, [Kell, 1968; Watters and Prinz, 1979]. As a result, they will not be considered here. Feierberg et al. [1982] measured partial reflectance spectra $(0.85-2.5 \mu \mathrm{m})$ of a series of pyroxene-metal mixtures and mathematical constructs of areal mixtures. The usefulness of the data is hampered by the lack of chemical data for the pyroxene (probably a pigeonite) and the lack of ultraviolet and visible wavelength data.

Orthopyroxene-metal mixture spectra are characterized by the presence of two major absorption bands in the 0.9-1.0 $\mu \mathrm{m}$ (band I) and 1.75-2.1 $\mu \mathrm{m}$ (band II) regions, both due to $\mathrm{Fe}^{24}$ crystal field transitions in the pyroxene. A large number of available pyroxene spectra were assembled from the literature in addition to those measured in this study to search for spectral systematics [Adams, 1968; Hunt and Sallsbury, 1970; Nash and Conel, 1974; Adams, 1974; Pleters, 1974; Adams, 1975; Adams et al., 1979; Singer, 1981; McFodden et al., 1982; Ml yamoto et al., 1983; Cloutls, 1985; Mustard et al., 1986]. Unfortunately, orthopyroxenes show wide, and as yet unexplained, variations in many spectral parameters such as reflectance ratios. This severely hampers the construction of high-quality deconvolution techniques for PYX-MET spectra. The calibrations found for these assemblages are not as comprehensive as those available for OLV-MET spectra.

The addition of meteoritic metal (with its red, featureless spectrum) to orthopyroxene changes a number of properties: overall reflectance is reduced; band II is reduced in intensity; the reflectance maxima near $0.7 \mu \mathrm{m}$ and $1.4 \mu \mathrm{m}$ (interband maximum) are both suppressed relative to longer wavelengths; and the band minima shift to shorter wavelengths (Figure 5). These effects are also seen in other PYX-MET spectra [Felerberg et al., 1982]. All orthopyroxenes, with the exception of the smallest grain sizes $(<5 \mu \mathrm{m})$ have a band area ratio (band $\mathrm{II}^{*} /$ band $\mathrm{I}^{*}$ [Cloutls et al., 1986b]) between 0.8 and 1.17 . The addition of metal causes a reduction of the band area ratio (Figure 6). A 75:25 PYX:MET mixture has an area ratio of 0.78 versus 1.00 for the pure pyroxene. At $50 \mathrm{wt} \%$ metal, for which two different pyroxenes were used, the area ratios are essentially identical. Band area ratio was found to be the most useful parameter for establishing metal content. Although ternary mixtures of pyroxene-metal-plagioclase were not examined in this study, the addition of even large amounts of plagioclase feldspar will not vary these results by more than a few percent [Nash and Conel, 1974; Mustard et al., 1986].

Highly comminuted, metal-free pyroxene shows a low band area ratio and may be confused with pyroxene-metal mixtures using this criterion alone. However, the smallest pyroxene fractions show a decrease in the reflectance ratio of the interband peak (1.4 $\mu \mathrm{m}$ maximum) to the local maximum near $0.7 \mu \mathrm{m}$. For fine-grained pyroxenes this ratio is $<1.2$ versus $>1.2$ for the PYX-MET spectra. This was found to be the sole criterion for separating these two types of assemblages when absolute reflectance is unknown.

Increasing metal content results in an increasingly red slope being imparted to the PYX-MET spectra. This is a potentially useful criterion except for the fact that pyroxene reflectance ratios are highly variable. Increasing metal content causes the intersection of a horizontal continuum tangent to the $1.4 \mu \mathrm{m}$ interband peak with the long-wavelength wing of band II to shift to shorter wavelengths. The addition of metal also tends to reduce most reflectance ratios. The ratio of the band II minimum reflectance to the local $0.7 \mu \mathrm{m}$ peak reflectance 


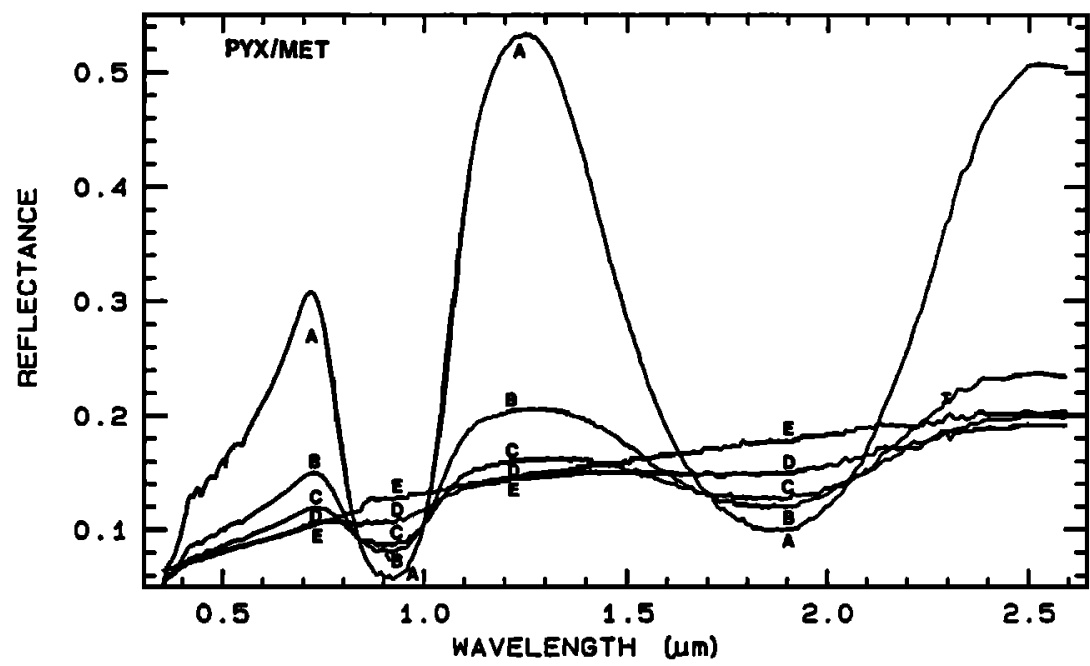

Fig. 5. Absolute reflectance spectra of the $45-90 \mu \mathrm{m}$ sized orthopyroxene + meteoritic metal mixtures. The numbers given for each spectrum indicate orthopyroxene (PYX117) and metal weight percentages, respectively (e.8., 75 wt \% orthopyroxene plus 25 wt \% metal is indicated as $75 / 25$ ). Spectrum $A=100 / 0$, spectrum $\mathrm{B}=75 / 25$, spectrum $\mathrm{C}=50 / 50$, spectrum $\mathrm{D}=25 / 75$, spectrum $\mathrm{E}=0 / 100$.

ranges from 1.1 to 3.3 in pure pyroxenes. The addition of $\mathbf{5 0}$ wt \% metal reduces the initial ratios in two chemically and spectrally distinct pyroxenes from 3.15 and 1.89 to 0.94 and 0.76 , respectively, a substantial decrease in variability (Figure 7). The grain size of the metal can be roughly constrained using this ratio, in conjunction with the band area ratio for metal abundance. Extrapolating from pure metal spectra, contours can be constructed on Figure 7 joining points of equal metal content. Plotting the reflectance ratio in the field of
Figure 7 will yield the metal grain size for the previously determined metal content. These construction lines have been omitted because of the lack of data for larger grain size pyroxene-metal mixtures.

The variability in pyroxene spectra is most problematic for particle size determinations, since reflectance ratios are traditionally the most effective means for determining this parameter, assuming absolute reflectance is unknown. Olivine grain size is best determined by the depth or intensity of the

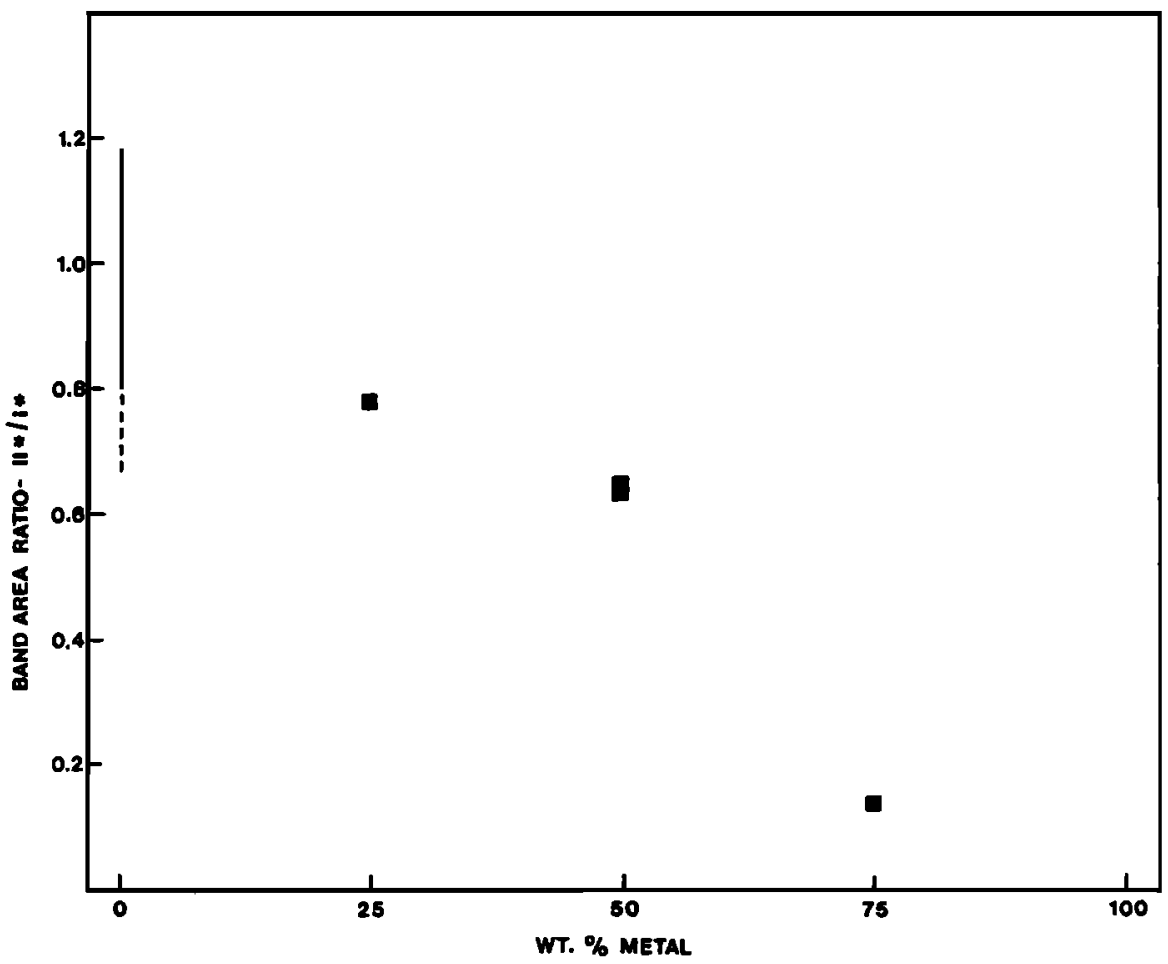

Fig. 6. Band area ratio as a function of metal abundance for pyroxene-metal mixtures. The range in band area ratio of pure pyroxenes is indicated by the vertical line at $0 \mathrm{wt} \%$ metal. The dashed extension represents very fine grained pyroxenes, which can be distinguished from pyroxene+metal mixtures by other means. 


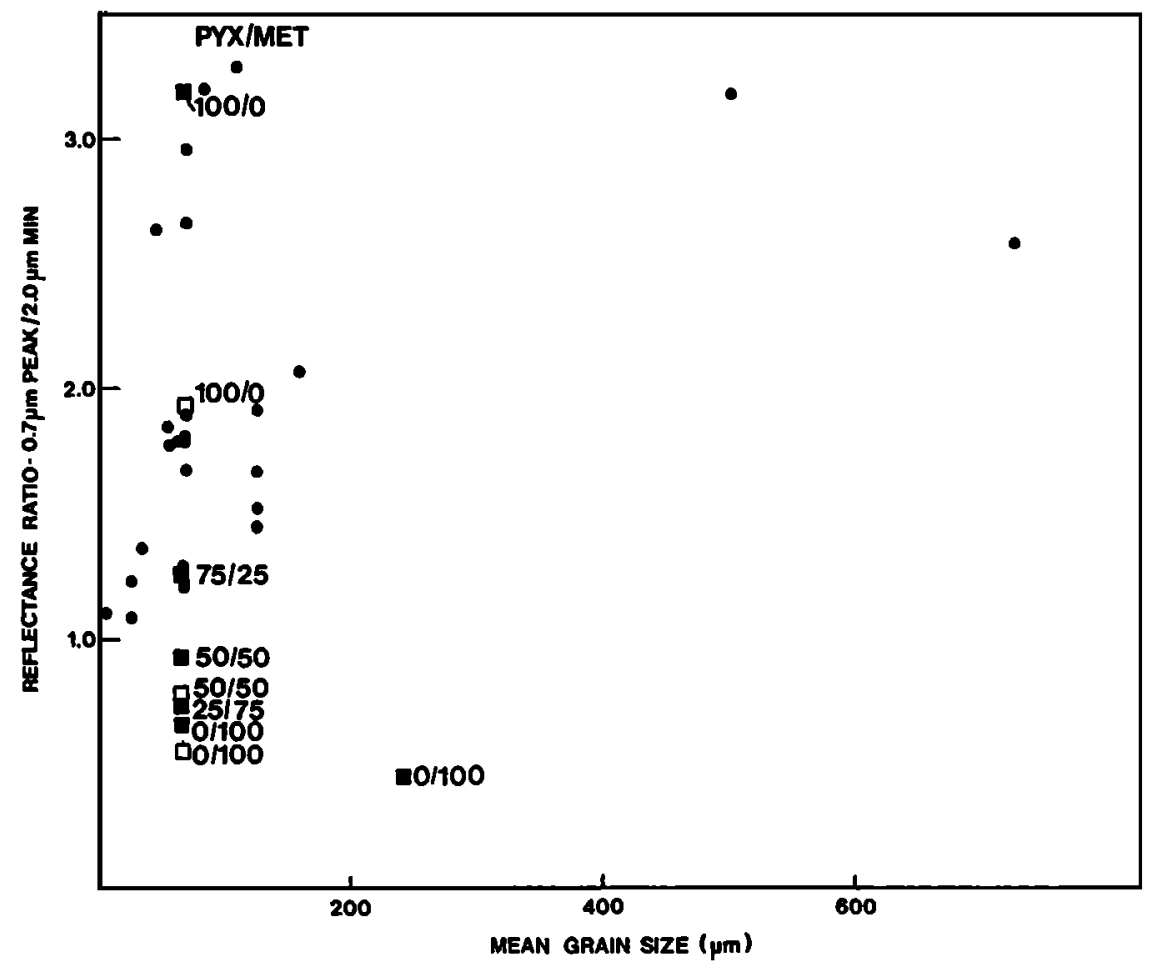

Fig. 7. Reflectance ratio of the local peak near $0.7 \mu \mathrm{m}$ to the band II minimum near $2 \mu \mathrm{m}$, as a function of grain size for pyroxene +metal spectra. Circles indicate pure orthopyroxenes. Two different pyroxene-metal series are indicated by solid and open squares. The numbers indicate pyroxene and metal weight percentages, respectively (e.8., $75 \mathrm{wt} \%$ pyroxene plus $25 \mathrm{wt} \%$ metal is indicated as $75 / 25$ ).

major $1 \mu \mathrm{m}$ absorption band. A similar approach to pyroxenes, measuring band depth as the ratio of the reflectance of the interband peak ( $1.4 \mu \mathrm{m}$ maximum) to the reflectance of the band I minimum, shows a general increase with increasing grain size, although there are a number of exceptions. In general, it appears that a peak:minimum ratio of -5.5 or less indicates a smaller pyroxene grain size (Figure 8 ). Corrections for metal content can be made in a manner analogous to the olivines (Figure 3).
The wavelength positions of the two major $\mathrm{Fe}^{2+}$ absorptions near $1 \mu \mathrm{m}$ and $2 \mu \mathrm{m}$ have been shown to shift to longer wavelengths with increasing iron content [Adams and McCord, 1972; Adams, 1974, 1975; Cloutts, 1985; Cloutls et al., 1986a,b; Aoyama et al., 1987]. All available orthopyroxene spectral data for which at least major element chemistries are available were reevaluated. While the sample size is small (15 samples), it appears that the substitution of aluminum for silicon in the tetrahedral sites results in absorption band minima shifting to

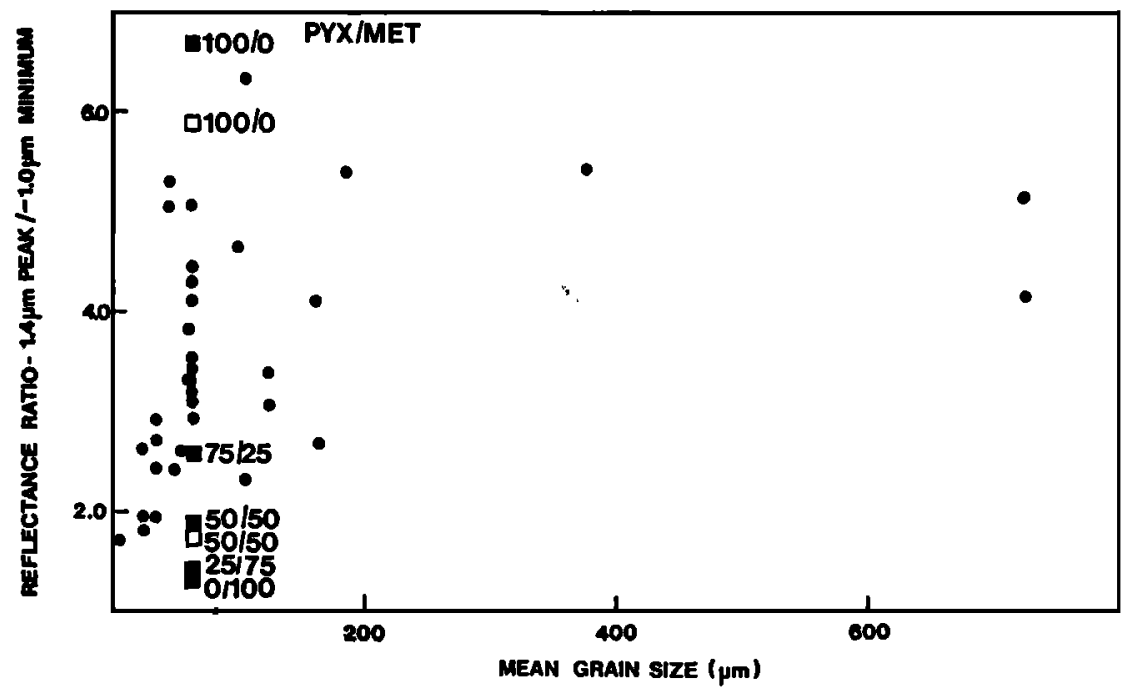

Fig. 8. Reflectance ratio of the interband peak near $1.4 \mu \mathrm{m}$ to the band I minimum near $1 \mu \mathrm{m}$, as a function of mean grain size. Symbols are the same as in Figure 7. 
shorter wavelengths, opposite to the trend found for increasing iron content. Both these trends are consistent with the different ionic radii of $\mathrm{Mg}^{2+}, \mathrm{Fe}^{2+}, \mathrm{Si}^{4+}$, and $\mathrm{Al}^{3+}$. The shift in the wavelength position of the band Il minimum due to changing iron content is greater than that for band I. When the separation of the two bands is plotted against the band II minimum position a very tight linear trend emerges which is very useful for determining iron content [Cloutls, 1985]. When higher aluminum content orthopyroxenes are included, the iron content of these samples is seriously underestimated using this criterion. Based on this admittedly small sample size, it appears that for every 1 wt \% increase in $\mathrm{Al}_{2} \mathrm{O}_{3}$, the ferrosilite (Fs) content is underestimated by $-5 \mathrm{~mol} \%$. The Fs contents of four high-aluminum pyroxenes $\left(>4 \mathrm{wt} \% \mathrm{Al}_{2} \mathrm{O}_{3}\right)$ are shown in Figure 9 . This systematic variation, if it proves to be real, may be of particular significance for lunar remote sensing, since lunar pyroxenes commonly contain some aluminum [Adams and McCord, 1972; Paplke et al., 1976]. No consistent spectral parameter has been found to differentiate between low - and high-aluminum pyroxenes. Using the wavelength positions of the band minima as indicators of pyroxene chemistry is the most useful criterion, but it provides only a lower limit on pyroxene ferrous iron content.

The presence of red-sloped metal causes both absorption band minima to shift to shorter wavelengths but to remain very close to the pure pyroxene trend (Figure 10). Each 25 wt \% increase in metal content shif ts the apparent Fe content of the pyroxenes downward by $\sim 8 \%$. Since metal content can be determined using other spectral parameters, its effect can be compensated for to yield the minimum Fs content.

The decline in band area ratios (Figure 6) with increasing metal content mimics a similar trend observed for increasing olivine content in olivine-pyroxene mixtures [Cloutls et al., 1986a]. On the basis of this criterion alone, PYX-MET and PYX-OLV assemblages may be confused. The simplest method for distinguishing among them is on the basis of the horizontal tangent intersection point. Pyroxene and pyroxene-metal mixtures have their intersection point at $<-1.1 \mu \mathrm{m}$, while in PYX-OLV spectra it occurs at $>-1.1 \mu \mathrm{m}$.

\section{Olivine-Pyroxene-Metal Mixtures}

A single olivine-pyroxene-metal (OLV:PYX:MET = 30:40:30) mixture and its metal-free counterpart (OLV:PYX =43:57) were spectrally characterized in order to examine briefly the general spectral properties that are present in these ternary assemblages (Figure 11). The spectral properties of olivine-pyroxene mixtures have been thoroughly examined by Singer [1981], Miyamoto et al. [1983], and Cloutis et al. [1986b]. When metal is added, it acts to largely counteract many of the effects of the olivine in terms of intersection point and band minima wavelength positions. There is no one spectral parameter which can be used to separate OLV-PYX-MET mixtures from OLV-PYX and PYX-MET assemblages.

The spectral properties of the ternary OLV-PYX-MET mixtures can be anticipated from the studies of the various binary mixtures. The predicted effects of the metal, narrowing of absorption bands and shifts of band minima and tangent intercepts to shorter wavelengths, are of fset to a large degree by the addition of olivine. Other effects such as reduction of the band area ratio are enhanced by the addition of olivine. These discrepancies in systematic spectral variations can be used to recognize the presence of olivine in a PYX-MET assemblage. The band area ratio can be used to set a very ef fective upper limit on metal abundance Applying the primary

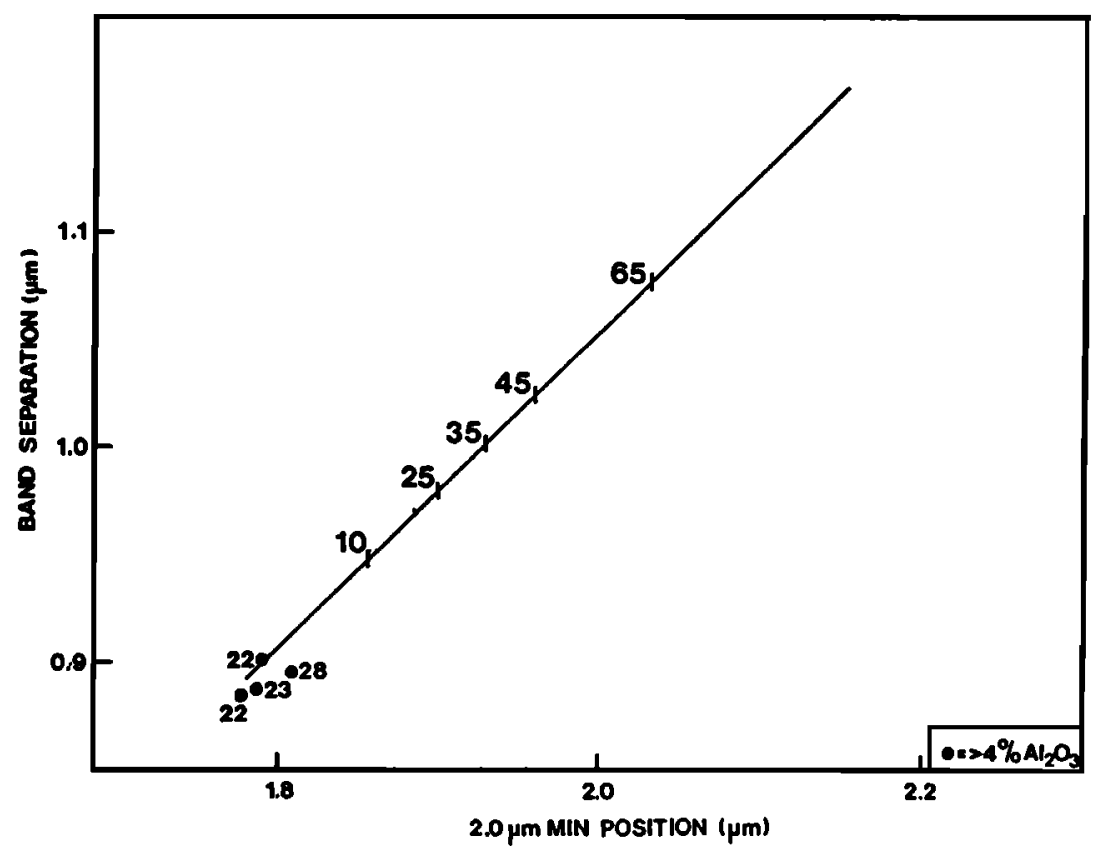

Fig. 9. Separation of the band I and band II minima (in microns) as a function of wavelength position of the band II minimum for orthopyroxenes show a linear trend. Both parameters increase with increasing iron content. The line represents a linear least squares fit to the data for a number of orthopyroxenes [Cloutts, 1985]. The numbers along the line indicate the iron content (mole percent ferrosilite) of low aluminum orthopyroxenes. The data for some high aluminum content orthopyroxenes $\left(>4 \% \mathrm{Al}_{2} \mathrm{O}_{3}\right)$ are plotted as circles along with their molar iron contents. The presence of aluminum seems to shift the absorption bands toward shorter wavelengths and lower apparent iron content. 


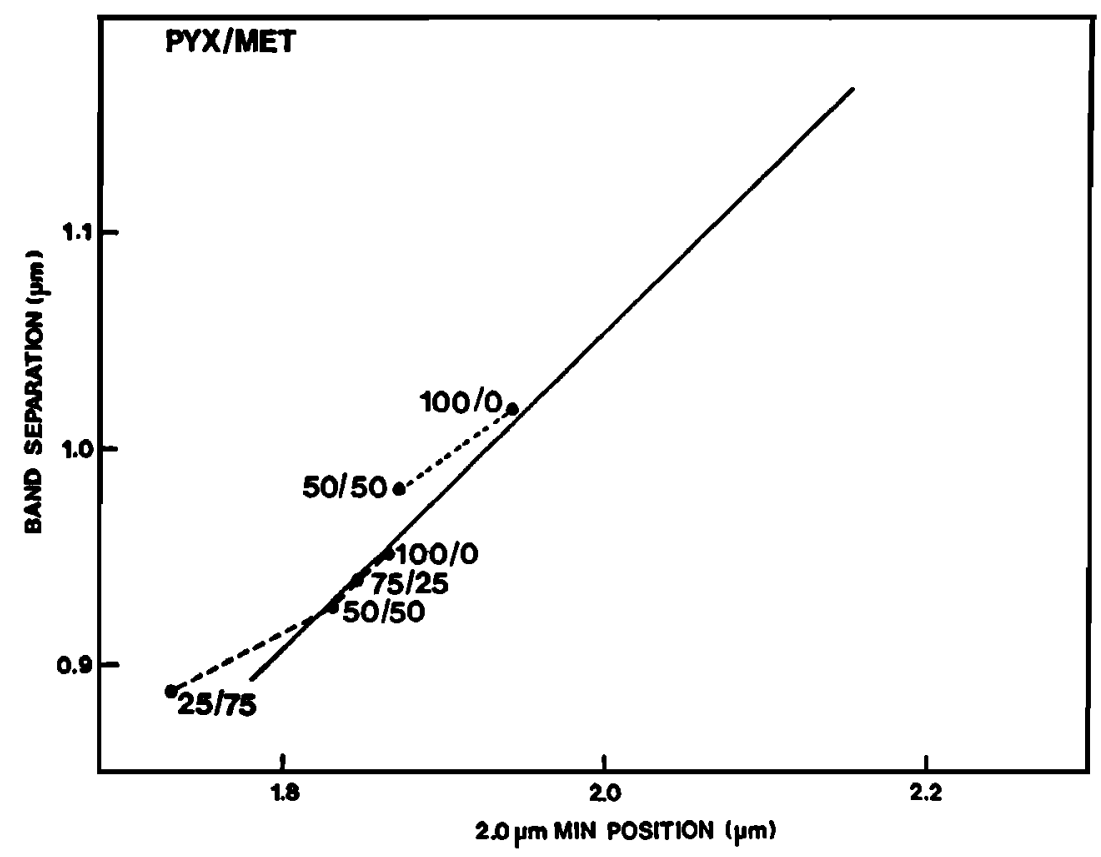

Fig. 10. Same as Figure 9 with the two orthopyroxene-metal series plotted. Orthopyroxene and metal abundances of the mixtures are indicated in the same way as in Figure 7.

PYX-MET calibration (Figure 6) to the ternary assemblage indicates a metal abundance of $-60 \%$ (i.e., PYX:MET = 40:60). If the mixture contained only pyroxene and metal, it should have a tangent intercept at $1.015 \pm .015 \mathrm{\mu m}$. It actually occurs at $1.10 \mu \mathrm{m}$ which is at the extreme high end of the pyroxene range, due to the broadening influence of the olivine band $I$. The 40:60 PYX:MET spectrum should have a band minimum at $0.896 \pm .007 \mu \mathrm{m}$, but again due to olivine, it occurs at $0.917 \mu \mathrm{m}$. These latter two calibrations for pyroxene are not shown because they do not form part of the pyroxene+metal calibrations. They show only general trends which are of lower precision than the band area ratio calibration. They are, however, very useful for reliably establishing the presenc of olivine. Olivine also causes a noticeable slope break to appear on the long wavelength wing of band I at $1.10-1.15 \mu \mathrm{m}$, in addition to the shift in band minimum and tangent intercept.

Olivine-pyroxene mixtures have band area ratios ranging from 0 to -1.2 , equal to the range for pyroxene-metal [Clouts et al., 1986b]. Enough spectral differences exist to distinguish these two types of assemblages. The horizontal tangent intercept in pyroxenes and PYX-MET spectra occurs between 0.9 and $1.13 \mu \mathrm{m}$ and in olivines between 1.44 and $1.63 \mu \mathrm{m}$.

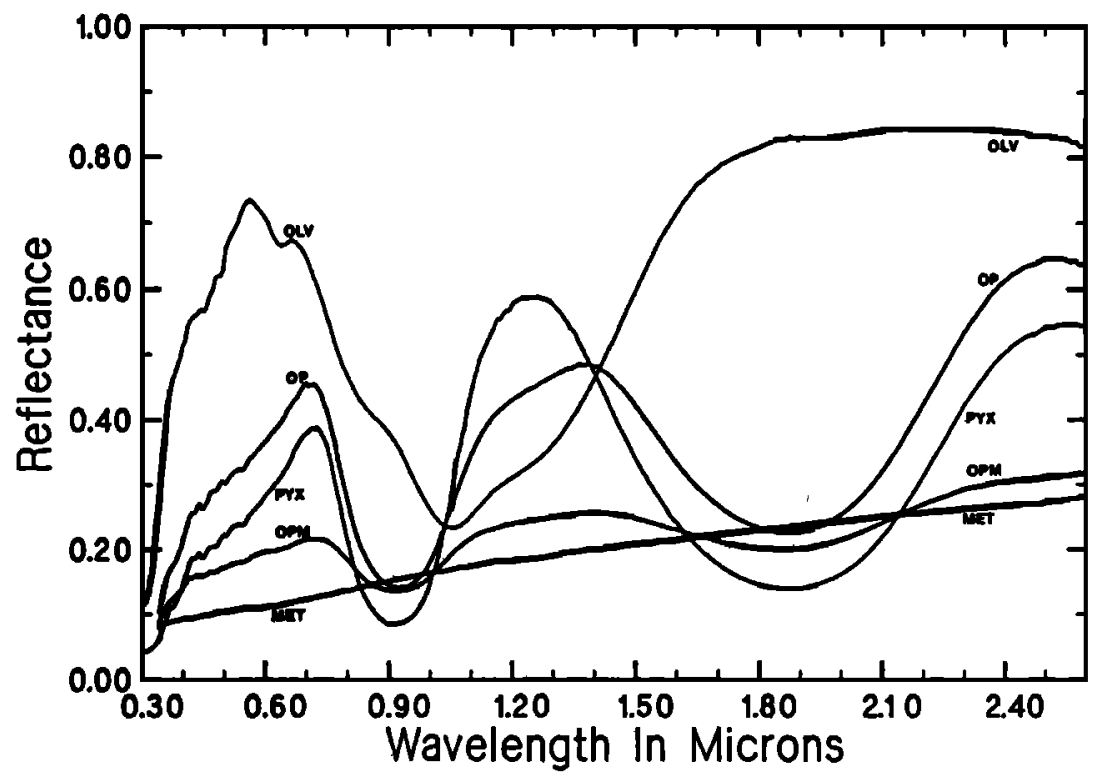

Fig. 11. Absolute reflectance spectra of $45-90 \mu \mathrm{m}$ sized $30 \%$ olivine $+40 \%$ pyroxene $+30 \%$ metal mixture (OPM), $43 \%$ olivine $+57 \%$ pyroxene mixture (OP), $100 \%$ olivine (OLV), $100 \%$ pyroxene (OPX), and $100 \%$ meteoritic metal (MET). 
Olivine-pyroxene spectra will have an intercept point between these two extremes. In many cases, particularly for approximately equal amounts of olivine and pyroxene, the 0.7 $\mu \mathrm{m}$ : interband peak ratio is $>1$, and the horizontal tangent intersection point misses band I completely, intersecting the long-wavelength wing of band II. This is seen in the reflectance spectra of many $H$ chondrites which have approximately the same proportions of OLV:PYX:MET as the ternary mixture [Chapman and Sallsbury, 1973; Gaffey, 1976]. This is probably due to the neutral nonred spectral nature of the metal in ordinary chondrites [Gaffey, 1986]. A 0.7 peak: interband peak ratio of $<\sim 0.8$ seems effectively to encompass metal-rich ternary assemblages and distinguishes them from metal-free or metal-poor binary OLV-PYX mixtures and ordinary chondrites. The separation is most pronounced when pyroxenes with a low initial $0.7 \mu \mathrm{m}$ peak:interband peak ratio are involved. A low ratio is characteristic of many meteoritic pyroxenes [Gaffey, 1976; McFadden et al., 1982; Mi yamoto et al., 1983].

One $\mathbf{H}$ chondrite (Tieschitz) has a tangent intersection point on band I, but it lies at $-1.22 \mu \mathrm{m}$ [Gaffey, 1976]. The absence of $a$ band $I$ intersection point or its presence at $>-1.1 \mu \mathrm{m}$ is characteristic of metal-free and/or dark and neutral opaque-bearing OLV-PYX assemblages (E.A. Cloutis et al., manuscript in preparation, 1990). Other characteristics shown by $\mathrm{H}$ chondrites which are inconsistent with metal-rich spectra are an interband peak at the high end or outside the pyroxene range, and a high $0.7 \mu \mathrm{m}$ peak:interband peak ratio. It can perhaps be argued that the carbon in ordinary chondrites may effectively suppress the red slope of the metal. A 99.5:0.5 wt \% mixture of meteoritic metal: amorphous carbon was spectrally characte-ized to test this hypothesis. The mixture involved 45.90 $\mathrm{\mu m}$ meteoritic metal (Odessa coarse octahedrite) and amorphous carbon with a grain size of $<0.023 \mu \mathrm{m}$, thoroughly mixed together. This amount of carbon is comparable to that found in $\mathrm{H}$ chondrites [Moore and Lewis, 1967]. The albedo of this amorphous carbon $(<1 \%)$ is substantially lower than other lampblacks used in mineral mixtures [Clark, 1983]. The normalized reflectance spectrum of the mixture matches the pure metal spectrum. The carbon suppresses the overall reflectance but preserves the red slope of the metal.

Metal grain size is probably also not a viable explanation for the flat overall spectral slope. Lower-grade enstatite chondrites have a smaller mean grain size of metal than the higher petrologic grades [Easton, 1983] buit show a redder slope than the coarser-grained samples [Sallsbury et al., 1975; Gaffey, 1976], even when the metal content is relatively constant [Mason, 1966; Ketl, 1968]. The amount of fine-grained metal in chondrites can be extrapolated from the results of Dodd [1976]. The probable abundance of submicron-sized metal in ordinary chondrites is $<<1 \%$. It appears that neither carbon nor comminuted metal can alter the spectral signature of an OLV-PYX-MET assemblage enough to produce an ordinary chondrite-like spectrum. The only feasible mechanism is to comminute a substantial portion of the metal to submicton grain sizes. Such a process, if applied to the entire assemblage, would also fragment the silicate grains to such a small size that their absorption bands would probably be indistinguishable. The spectral properties of pure metal from ordinary chondrites have not been determined. However, the reflectance spectra of metal-rich ordinary chondrite separates do not show the red slope characteristic of iron meteorite metal [Gaffey, 1986]. Thus the laboratory mafic silicate+metal spectra do not provide a good spectral match to ordinary chondrites.
Plagioclase-pyroxene spectra may mimic many of the features of the ternary mixture spectra. These binary mixtures are largely outside the scope of this study, but an initial examination of available plagioclase-pyroxene spectra suggests that the slope break on the long wavelength wing of band $I$ is confined to wavelengths $>1.18 \mu \mathrm{m}$.

Clinopyroxene-orthopyroxene-metal spectra may also be confused with those of olivine-orthopyroxene-metal. Enough spectral differences probably exist to distinguish these ternary assemblages. Comparing clinopyroxenes and olivines, the former show reflectance maxima near $0.8 \mu \mathrm{m}$, a second absorption band between 2.15 and $2.40 \mu \mathrm{m}$, and band minima at wavelengths below $1.06 \mu \mathrm{m}$, compared with reflectance maxima between 0.5 and $0.7 \mu \mathrm{m}$, no band II, and band I minima at $>1.05 \mu \mathrm{m}$ in olivines [Adams, 1968, 1974, 1975; Gaffey, 1976; Miyamoto et al., 1983; Cloutis, 1985; Hirol et al., 1985; Cloutls et al., 1986a].

\section{APPLICATION TO ASTEROID SPECTRA}

The various spectral parameters that correlate with the physical and chemical properties of mafic silicate+metal mixtures can be applied to the analysis of the reflectance spectra of asteroids suspected of possessing mafic silicate +metal on their surfaces. The likeliest candidates are the $S$ - and $A$-class asteroids [Bell et al., 1984a,b; Crulkshank and Hartmann, 1984; Gaffey, 1984]. A representative member of each group was selected for interpretation on the basis of the spectral parameters outlined in the previous section for characterizing mafic silicate + metal spectra.

\section{S-Class Asterold (8) Flora}

Asteroid (8) Flora is a representative member of the S-class asteroid group for which spectral [Chapman and Gaffey, 1979; Feterberg et al., 1982; Gaffey, 1984; Gaffey et al., 1988; Gaffey, 1989], polarimetric [Veverka, 1971, 1973; Morrison and Zellner, 1979], radar [Ostro et al., 1985], and photometric data [Veeder et al., 1978] are available. The reflectance spectrum of Flora shows a number of features which are characteristic of an olivine + pyroxene + metal assemblage (Figure 12). The average reflectance spectrum has an interband peak wavelength

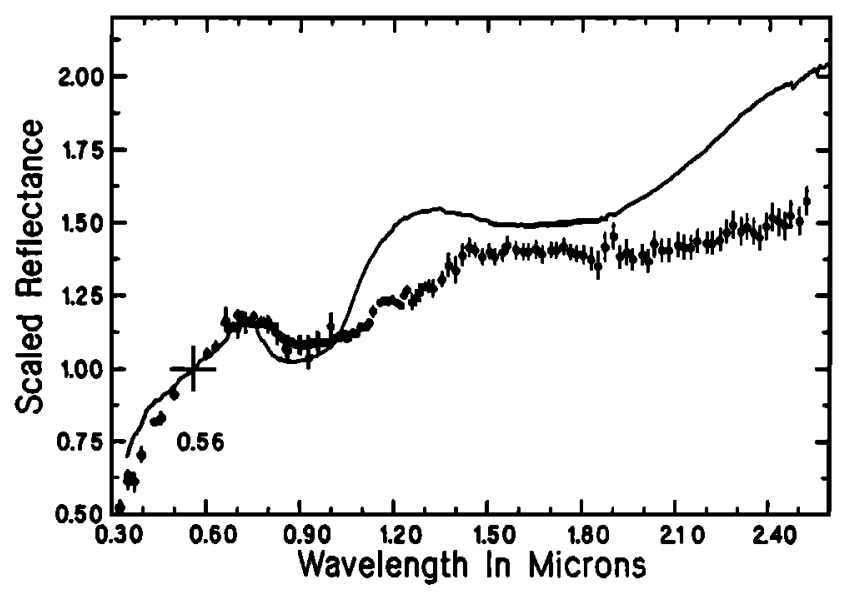

Fig. 12. Normalized reflectance spectra (scaled to 1 at 0.56 $\mu \mathrm{m}$ ) of asteroid (8) Flora (points) and a computer-generated additive assemblage of $30 \% 50 / 50$ OLV/MET, 60\% 25/75 OLV/MET, and 10\% PYX117 (line). The additive assemblage represents an approximate analog to the derived surface assemblage of Flora. 
position at the high end of the orthopyroxene field, an inflection point on the long-wavelength wing of band 1 near $1.10 \mu \mathrm{m}$, and a band I tangent intersection point outside the pyroxene field $(-1.12 \mu \mathrm{m})$, all of which are indicative of olivine. The spectrum of Flora also has a high interband peak:0.7 $\mu \mathrm{m}$ peak ratio $(1.22)$ and a band II intersection point at $<2.3$ $\mu \mathrm{m}$, both of which are indicative of metal.

The band I minimum and center wavelength positions, as determined by Gaffey [1984], are at $0.925 \mu \mathrm{m}$ and $1.001 \mu \mathrm{m}$, respectively. Large metal grains could account for this difference but the interband peak:0.7 $\mu \mathrm{m}$ peak ratio and tangent intersection point are indicative of a fine-grained metal $(<90$ $\mu \mathrm{m}$ sized). The difference between the wavelength position of the band I minimum and continuum-removed center can be explained by the presence of partially overlapping olivine and orthopyroxene absorption bands of approximately equal intensity. The band I minimum position $(0.925 \mu \mathrm{m})$ indicates that an orthopyroxene is slightly dominant [Cloutis et al., 1986b]. Dividing out the red-sloped continuum results in the olivine absorption band appearing slightly more dominant $(1: 001 \mu \mathrm{m})$. Olivine and orthopyroxene absorption bands are of approximately equal intensity at $80 / 20$ OLV/PYX [Cloutis, 1985; Cloutis et al., 1986b]. The wavelength position of the band center, separation between band $I$ and band II, and band $\mathrm{II}^{*} /$ band $\mathrm{I}^{*}$ area ratio are all consistent with this interpretation.

The intersection point of the horizontal continuum for the Flora spectrum is at $1.12 \mu \mathrm{m}$ but should occur at $>1.46 \mu \mathrm{m}$ if no metal is present. The calibrations for metal abundances in binary mixtures indicate that either 40 wt \% metal is present (if the assemblage contains only olivine + metal, Figure 2) or 85 wt \% metal (if the assemblage contains only orthopyroxene + metal, Figure 6). Given the dominance of olivine over pyroxene, a weighted average of $50 \%$ metal is probable. The interband peak:band 1 minimum reflectance ratio of 1.22 indicates a substantial fine-grained $(<45 \mu \mathrm{m}$ sized) mafic silicate component using both the olivine (Figure 3) and pyroxene (Figure 8) spectral criteria. The absolute reflectance of Flora (22\% at $0.56 \mu \mathrm{m}$ [Gaffey et al., 1988]) is higher than that of the $50 / 50$ OLV/MET laboratory spectrum containing 45-90 $\mu \mathrm{m}$-sized materials. This is further evidence for a significant fine-grained surface component on Flora, even though the absolute reflectances of the laboratory and telescopic spectra are not directly comparable [Hapke, 1981]. The reflectance spectra of mixtures containing a range of particle sizes appear most like spectra of samples containing only fine-grained particles, both having high overall reflectance [Cloutis, 1985].

The wavelength position of band II is a useful indicator of pyroxene chemistry because it is unaffected by the presence of olivine [Clouts, 1985; Cloutts et al., 1986a]. After correcting the band minima positions of Flora for $50 \%$ metal and $40 \%$ olivine, the mean orthopyroxene composition is determined to be Fs 30. The uncertainties in the wavelength position of band II $(1.9 \pm 0.1 \mu \mathrm{m})$ bracket a range of Fs contents of 5-65 mol \%. If clinopyroxene is also present on Flora, as seems likely because of the lack of an appreciable red slope beyond $2.0 \mu \mathrm{m}$, then the Fs content of the orthopyroxene represents a maximum value. Orthopyroxene+clinopyroxene spectra usually show complex band II absorption features with the band minimum occuring between the two end member values [Cloutis, 1985]. If no clinopyroxene is assumed, and also assuming that the surface assemblage of Flora is an equilibrium mixture, the olivine must be a high-iron variety $(\mathrm{Fa}=35 \pm 10)$. The olivine composition cannot be independently determined because the band I position, which is the primary method for determining this parameter, was used to constrain the OLV/PYX ratio.

An olivine+pyroxene+metal assemblage corresponding to that derived for Flora was not spectrally characterized. However an additive mixture of $30 \% 50 / 50$ OLV/MET, $60 \%$ 25/75 OLV/MET, and 10\% orthopyroxene (PYX117) provides a reasonable match to the low wavelength spectrum of Flora (Figure 12). Because areal and intimate mixtures are not spectrally equivalent, the data are not directly comparable but do provide a reasonable approximation to an intimate mixture. Orthopyroxene is a more intense absorber than olivine. Thus the $10 \%$ orthopyroxene in the additive mixture is an upper limit since $10 \%$ orthopyroxene in an intimate mixture would show even more pronounced absorption features than the additive mixture. The simulated spectrum effectively reproduces the broadness of the absorption feature near $1 \mu \mathrm{m}$ and the reflectance drop-off at wavelengths shorter than 0.7 $\mu \mathrm{m}$. The simulated spectrum is consistently brighter than Flora at wavelengths greater than $1.1 \mu \mathrm{m}$. This discrepancy would be reduced if a smaller grain size metal, which has a less red slope at longer wavelengths than coasser metal, were used [Cloutls et al., 1990]. A few weight percent of clinopyroxene would also improve the fit at longer wavelengths and in the ultraviolet region.

A fine-grained mafic silicate +metal component on Flora is supported by the polarimetric data. The polarimetric parameters $\boldsymbol{P}_{\min }$ and $\alpha_{0}$ for Flora [Veverka, 1971, 1973; Zellner et al., 1977; Morrison and Zellner, 1979] lie in the field for fine-grained powders and outside the range for most ordinary chondrites [Zellner et al., 1977; Dollfus et al., 1979; Geake and Dollfus, 1986]. A synthesis of the available laboratory polarimetric data suggests that the data for Flora are consistent with an assemblage containing a significant $<45 \mu \mathrm{m}$ sized component. The observetional radar data for Flora are also consistent with a mafic silicate + metal assemblage of typical lunar regolith porosities [Ostro et al., 1985].

On the basis of available observational data, the surface of Flora seems to be composed of -50 wt $\%$ metal, $-40 \mathrm{wt} \%$ olivine $(F a=35 \pm 10),-10$ wt $\%$ orthopyroxene ( $F s=30: 15)$, and perhaps a few percent clinopyroxene. There are a range of grain sizes present, with a significant fine-grained $(<45 \mu \mathrm{m}$ sized) component. The determined average surface assemblage is in good agreement with earlier interpretations [Gaffey, 1984].

A 50/40/10 MET/OLV/PYX assemblage does not correspond to any known meteorite. Pallasites are similar in terms of metal:olivine ratios and olivine composition but lack appreciable amounts of pyroxene [Buseck, 1977]. Lodranites are differentiated meteorites composed predominantly of metal, olivine and pyroxene [Nagahara and Ozawa, 1986]. The Antarctic lodranite described by Yanat and Kofima [1983] contains an olivine:pyroxene ratio similar to that determined for Flora but is deficient in metal (13.6 wt \%), due in part to terrestrial weathering. If the original metal content were $50 \mathrm{wt}$ $\mathscr{F}_{0}$, it would be very similar to the derived surface composition of Flora.

\section{A-Class Asteroid (446) Aeternitas}

A-class asteroids have been interpreted to be olivine-rich objects with various amounts of metal and perhaps minor amounts of pyroxene [Bell et al., 1984a,b; Crulkshank and Hartmann, 1984]. Unlike Flora, no polarimetric or radar data are available for these objects. (446) Aeternitas is perhaps the best characterized member of this group [Chapman and 
Gaffey, 1979; Veeder et al., 1983; Bell et al., 1984a,b,1988; Gaffey et al., 1988; Gaffey, 1989].

The reflectance spectrum of Aeternitas (Figure 13) has features characteristic of olivine + metal: a prominent absorption band near $1 \mu \mathrm{m}$; an inflection near $1.25 \mu \mathrm{m}$; and a high interband peak:0.7 $\mu \mathrm{m}$ peak ratio (1.7). A small amount of pyroxene is indicated by the flatness of the reflectance spectrum in the 1.6-2.4 $\mu \mathrm{m}$ interval and the presence of weak absorption bands in this region which are not characteristic of olivine [King and Ridley, 1987].

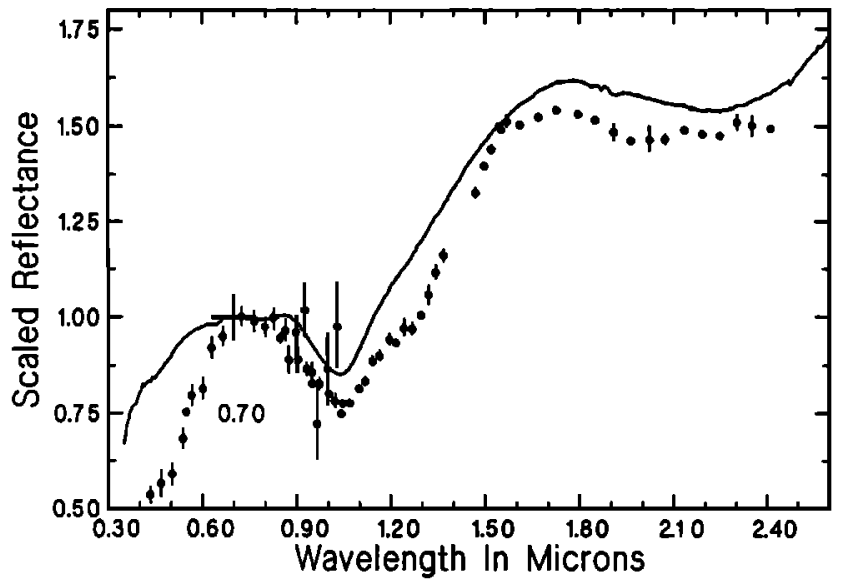

Fig. 13. Normalized reflectance spectra (scaled to 1 at 0.70 $\mu \mathrm{m}$ ) of asteroid (446) Aeternitas (points) and a computer-generated additive assemblage of $60 \% \quad 50 / 50$ OLV/MET, $20 \% 75 / 25 \mathrm{OLV} / \mathrm{MET}$, and $20 \%$ clinopyroxene (line). The additive assemblage represents an approximate analog to the derived surface assemblage of Aeternitas.

The wavelength position of band I can be used to place constraints on pyroxene abundances. If orthopyroxene is the dominant form of pyroxene, the olivine:pyroxene ratio must be $>9: 1$, because more than $10 \%$ orthopyroxene would shif the band I minimum of Aeternitas $(1.057 \mu \mathrm{m})$ to much shorter wavelengths and introduce a significant absorption band near $1.9 \mathrm{\mu m}$ [Cloutls, 1985; Cloutls et al., 1986b]. If clinopyroxene is the dominant form of pyroxene, its abundance can be as high as $-30 \mathrm{wt} \%$ before significant spectral alteration is seen.

The mafic silicate+metal spectral calibrations applied to Aeternitas provide some discrepant interpretations. Assuming for the moment that the spectrum of Aeternitas indicates only olivine + metal, the tangent intersection position (Figure 2 ) indicates $40 \mathrm{wt} \%$ metal and $60 \mathrm{wt} \%$ olivine. The $1.8 \mu \mathrm{m}: 1.0 \mu \mathrm{m}$ reflectance ratio (2.00) corresponds to a grain size of $-100-200$ $\mu \mathrm{m}$ (Figure 3 ). The band 1 minimum wavelength position is fairly insensitive to small amounts of pyroxene and, after correcting for $40 \%$ metal and $10 \%$ orthopyroxene, is $1.064 \pm 0.003 \mu \mathrm{m}$. This corresponds to an olivine composition of $\mathrm{Fa}=20 \pm 10$.

Two weak absorption bands seem to be present at $1.96 \mu \mathrm{m}$ and $2.26 \mu \mathrm{m}$. A mixture of $25 \%$ orthopyroxene with $75 \%$ clinopyroxene could account for these bands. A 25/75 orthopyroxene/clinopyroxene mixture is indicated by the fact that both these absorption bands are of approximately equal intensity [Cloutls, 1985]. The wavelength positions of the bands, uncorrected for metal content, correspond to an ortho- pyroxene or pigeonite containing $45 \mathrm{~mol} \mathrm{\%} \mathrm{Fs} \mathrm{and} \mathrm{a} \mathrm{clinopyro-}$ xene containing $17 \mathrm{~mol} \% \mathrm{Fs}$. This is a roughly equilibrium two-pyroxene assemblage [Roblnson, 1980]. Orthopyroxene+ clinopyroxene spectra of ten show shifts in band II minima wavelength positions due to overlaps of their respective absorption bands. Therefore the calculated Fs contents of the pyroxenes are upper limits.

The reflectance spectrum of Aeternitas bears little superficial resemblance to the $50 / 50$ olivine/metal spectrum. The former has a much more pronounced reflectance drop-off in the ultraviolet, a much higher interband peak:0.7 $\mu \mathrm{m}$ peak ratio and a flatter slope in the $1.7-2.5 \mu \mathrm{m}$ region. None of these factors serve as primary spectral deconvolution parameters but are nevertheless useful for determining whether reflectance spectra represent metal plus a single mafic silicate.

The absolute reflectance spectrum of Aeternitas is brighter than any of the olivine + metal laboratory spectra $(13-26 \%$ at $0.56 \mu \mathrm{m}$, Figure 1). Gaffey et al. [1988] determined an absolute reflectance of $37 \%$ at $0.56 \mu \mathrm{m}$, while Veeder et al. [1983] determined a geometric albedo of $17 \%$. Once again, it should be noted that laboratory reflectance spectra are not directly comparable to telescopic spectra [Hapke, 1981]. If the mean grain size determination for Aeternitas is correct (100-200 $\mu \mathrm{m})$, then the absolute reflectance of Aeternitas should be lower and not higher than the laboratory spectra, since the albedo of olivine and metal decreases with increasing grain size [King and Rldley, 1987; Brttt and Pleters, 1988; Clouts et al., 1990]. This discrepancy may not be as significant as the laboratory data indicate because iron meteorite slabs and powders show large variations in absolute albedo (7-29\% at 0.56 $\mathrm{m}$ [Johnson and Fanale, 1973; Gaffey, 1976; Brttt and Pieters, 1988; Cloutis et al., 1990]).

The meteoritic metal used in this study has a redder spectral slope than metal spectra measured by the other investigators cited above. The reflectance spectrum of Aeternitas, as measured by the interband peak:0.7 $\mu \mathrm{m}$ peak, is even redder than the pure metal spectrum. This strongly suggests that an additional phase is present which has a high interband peak:0.7 $\mu \mathrm{m}$ peak ratio. The likeliest candidates are orthopyroxene and clinopyroxene because they can also account for the absorption features present in the $2 \mu \mathrm{m}$ region.

Various additive mixtures of OLV/MET with orthopyroxene and clinopyroxene have been examined in an attempt to reproduce the spectrum of Aeternitas. A good overall match to the spectrum of Aeternitas was found for an additive mixture of $60 \% 50 / 50$ OLV/MET, $20 \% 75 / 25$ OLV/MET, and $20 \%$ clinopyroxene $\left(\mathrm{En}_{43} \mathrm{Fs}_{14} \mathrm{Wo}_{43}\right)$, all $45-90 \mu \mathrm{m}$ sized samples. The only region of mismatch is the 0.35-0.65 $\mu \mathrm{m}$ region (Figure 13). Clinopyroxene in intimate association with olivine + metal would probably show a greater reflectance decline in this region than the mathematical construct because clinopyroxene normally shows a steep reflectance decline at wavelengths shorter than $-0.65 \mu \mathrm{m}$ which cannot be accurately reproduced by the additive mixtures. The absolute reflectance of the construct $(14 \%$ at $0.56 \mu \mathrm{m})$ is less than Aeternitas. However, the absolute reflectance of olivine and clinopyroxene can be up to a factor of 2 higher for $0-45 \mu \mathrm{m}$ sized samples versus 45-90 $\mu \mathrm{m}$ sized samples [Cloutis, 1985], while metal shows a $20 \%$ reflectance increase with a similar diminution in grain size [Cloutis et al., 1990].

The variations in absolute reflectance due to changes in grain size and the variations seen in meteoritic metal measured by different investigators compared to the absolute reflectance of Aeternitas require that the surface of the asteroid possess a 
significant amount of fine-grained ( $<45 \mu \mathrm{m}$ sized) material. This of course is at odds with the grain size determination made earlier, suggesting $100-200 \mu \mathrm{m}$ sized grains. The grain size determination based on the $1.8 \mu \mathrm{m}: 1.0 \mu \mathrm{m}$ reflectance ratio (Figure 3) would give higher values if clinopyroxene were present because clinopyroxenes commonly have high $1.8 \mu \mathrm{m}: 1.0$ $\mu \mathrm{m}$ reflectance ratios. An overestimate of metal abundance would also result because clinopyroxenes tend to have low reflectances in the region of the $0.7 \mu \mathrm{m}$ peak. The reduced Ieflectance of the $0.7 \mu \mathrm{m}$ peak, due to the presence of clinopyroxene, tends to shift the tangent intersection point (Figure 2) toward lower values, corresponding to higher apparent metal contents.

Clinopyroxene +olivine spectra are dominated by the clinopyroxene [Cloutts, 1985]. The mathematica] construct of Aeternitas thus provides an upper limit on pyroxene abundances. Band depth analysis suggests that in the region of band I, the clinopyroxene band is approximately twice as intense as the olivine. The orthopyroxene band $I$ is approximately four times as intense as the olivine band I [Cloutis, 1985].

When factored in with the previously determined $75 / 25$ clinopyroxene/orthopyroxene ratio and the effect of clinopyroxene on metal content determination, the most consistent surface assemblage for Aeternitas is -55 wt $\%$ olivine, $7 \%$ clinopyroxene, $-3 \%$ orthopyroxene, and $-35 \%$ metal. The composition of the olivine appears to be $\mathrm{Fa}=20 \pm 10$. If the mafic silicates on Aeternitas represent an equilibrium assemblage, the corresponding pyroxenes would have compositions of approximately $F_{S}=15$ (orthopyroxene) and $F s=5$ (clinopyroxene). These values are well within the range previously determined using Band II positions. The mineral abundances determined by Bell et al. $[1984 a, b]$ for Aeternitas ( $40 \%$ olivine, $0-10 \%$ pyroxene, $50-60 \%$ metal) are in good agreement with the current interpretation.

There are no known meteorites with mineral abundances and compositions similar to that determined for Aeternitas, but the Eagle Station subgroup of pallasites [Dodd, 1981] are closest in terms of metal:olivine ratio and olivine composition. As was the case for Flora, the pallasites lack the necessary amounts of pyroxene required by spectral considerations.

\section{SUMMARY}

Olivine-metal, orthopyroxene-metal, and olivine-orthopyroxene-metal mixtures each possess unique spectral properties. A cursory examination of the reflectance spectrum of an unknown is usually sufficient to identify the spectrally significant minerals present. Various spectral parameters which do not rely on a knowledge of the absolute reflectance can be used to place severe constraints on assemblage properties such as phase abundances, major element chemistries of the mafic silicates, and particle sizes. Each of these properties has important implications for unravelling the history of the target. Each type of assemblage must be deconvolved in a systematic manner to obtain the maximum amount of compositional information.

Olivine and olivine-metal assemblages can be recognized by the presence of only one major absorption band near $1 \mu \mathrm{m}$, and a reflectance minimum between 1.0 and $1.1 \mu \mathrm{m}$. Systematic deconvolution requires determining the horizontal tangent intersection point for metal abundance (Figure 2), the $1.8 /$ band I minimum reflectance ratio for olivine grain size
(Figure 3), and the band I minimum wavelength position for olivine iron content (Figure 4). The parameters determined at each stage are used to correct subsequent calibrations.

Orthopyroxenes show a much wider range of spectral properties than olivine. The derived spectral deconvolution procedures are consequently of lower accuracy. Orthopyroxene and orthopyroxene-metal assemblages are recognized by the presence of absorption bands between 0.8-0.95 $\mu \mathrm{m}$ and 1.6-2.0 $\mu \mathrm{m}$, a reflectance maximum between 0.64 and $0.78 \mu \mathrm{m}$, a horizontal tangent intersection point between 0.9 and $1.1 \mu \mathrm{m}$, an interband peak between 1.23 and $1.36 \mu \mathrm{m}$, and no slope break at 1.10-1.15 $\mu \mathrm{m}$. Systematic deconvolution involves determining the band $\mathrm{II}^{*} /$ band $\mathrm{I}^{*}$ area ratio for metal abundance (Figure 6), the $0.7 \mathrm{\mu m}$ peak/band II minimum reflectance ratio for metal grain size (Figure 7), the interband peak:band I minimum reflectance ratio for pyroxene grain size (Figure 8), and the band minima separation versus band II minimum wavelength position for pyroxene chemistry (Figure 10). The parameters determined at each stage are used to correct subsequent calibration steps.

Olivine-orthopyroxene-metal assemblages show spectral properties intermediate between the three end-members. However, not all parameters vary to the same degree, and these variations can be used to identify, at a minimum, the spectrally significant phases. Pyroxene is a much more intense absorber than olivine and hence tends to dominate silicate absorption features. Away from absorption band minima, olivine features such as band broadening, interband maximum wavelength position, and a slope break at 1.10-1.15 $\mu \mathrm{m}$ can be recognized. These features allow some constraints to be placed on the relative abundances of the various minerals.

The presence of clinopyroxene or plagioclase adds an additional level of complexity to the analysis. As yet, no effective spectral deconvolution techniques have been developed for quaternary mixtures, but merely identifying the presence of other phases is of ten sufficient to permit judicious application of the calibrations.

Reanalysis of the reflectance spectra of asteroids (8) Flora (S-class) and (446) Aeternitas (A-class), on the basis of the laboratory spectra shows that previous interpretations of their surface assemblages are largely consistent with the new analyses. The surface of Flora seems to consist of $-50 \mathrm{wt} \%$ metal, $-40 \mathrm{wt} \%$ olivine, $-10 \mathrm{wt} \%$ orthopyroxene, and perhaps a few weight percent clinopyroxene. The mafic silicates appear to be high-iron varieties. The olivine composition is determined to be $F a=35 \pm 10$, while the orthopyroxene is $F s=30_{-25}^{+35}$. A substantial portion of the surface materials consist of fine-grained ( $<45 \mu \mathrm{m}$ sized) particles.

The surface of Aeternitas is interpreted to consist of $-35 \mathrm{wt}$ $\%$ metal, $-55 \mathrm{wt} \%$ olivine, $-7 \mathrm{wt} \%$ clinopyroxene, and $-3 \mathrm{wt} \%$ orthopyroxene. The mafic silicates appear to be more magnesium-tich than those on Flora, although the pyroxene compositions are poorly constrained. The olivine contains $20 \pm 10 \% \mathrm{Fa}$, the clinopyroxene is constrained to $<17 \mathrm{~mol} \% \mathrm{Fs}$, and the orthopyroxene is constrained to $<45 \mathrm{~mol} \%$ Fs. A significant amount of the surface materials are fine-grained $(<45$ $\mu \mathrm{m}$ sized particles). The spectral differences between Flora and Aeternitas can be attributed to differences in particle sizes of the surface materials, particularly the metal, and to differences in mafic silicate abundances and compositions. On the basis of the derived surface assemblages, neither asteroid is a plausible parent body for the ordinary chondrites, although both asteroids may have affinities to the pallasites and Flora may have a surface assemblage similar to at least one lodranite. 
Acknowledgments. This study was supported by grants-in-aid of research from the Central Research Fund of the University of Alberta (to D.G.W.S.), from the Geological Society of America (\#3741-87) and Sigma Xi-The Scientific Research Society (to E.A.C.), and NASA Planetary Geology and Geophysics grant NAGW 642 (to M.J.G.). Electron microprobe analysis of the samples was made possible through the assistance of E.D. Ghent and John Machacek at the University of Calgary. Some of the mafic silicate samples were obtained through the assistance and patience of John S. White and Pete Dunn of the Smithsonian Institution National Museum of Natural History. Thanks to Roger N. Clark and Greg Swayze of the U.S. Geological Survey, and Carle Pieters and Stephen Pratt of Brown University for access to the spectrometer facility and NASA RELAB spectrometer at their respective institutions. Thanks also to Doug Hube, Ron Eyton, Joseph Veverka, and Jonathan Gradie for their helpful reviews of the manuscript and to Jeffrey Bell for permission to reproduce the asteroid spectra.

\section{REFERENCES}

Adams, J.B., Lunar and martian surface materials: Petrologic significance of absorption bands in the near-infrared, Science, 159, 1453-1455, 1968.

Adams, J.B., Visible and near-infrared diffuse reflectance spectra of pyroxenes as applied to remote sensing of solid objects in the solar system, J. Geophys. Res., 79, 4829-4836, 1974.

Adams, J.B., Interpretation of visible and near-infrared diffuse reflectance spectra of pyroxenes and other rock-forming minerals, in Infrared and Raman Spectroscopy of Lunar and Terrestrial Minerals, edited by C. Karr Jr., pp. 91-116, Academic, San Diego, Calif., 1975.

Adams, J.B., and T.B. McCord, Electronic spectra of pyroxenes and interpretation of telescopic spectral reflectivity curves of the Moon, Proc. Lunar Sct. Conf., 3rd, 3021-3034, 1972.

Adams, J.B., F. Horz, and R.V. Gibbons, Effects of shock-loading on the reflectance spectra of plagioclase, pyroxene, and glass (abstract), Lunar Planet. Scl. Conf., $X$, $1-3,1979$.

Anders, E., Most stony meteorites come from the asteroid belt, Asteroids: An Exploration Assessment, edited by D. Morrison and W.C. Wells, NASA Conf. Publ., CP-2053, 57-75, 1978.

Aoyama, T., T. Hiroi, M. Miyamoto, and H. Takeda, Absorption spectra and bulk chemical composition of achondritic polymict breccias with reference to characterization of the surface of Vesta-like asteroids (abstract), Lunar Planet. Scl. Conf., XVIII, 27-28, 1987.

Auten, T.A., On the brittleness of Gibeon meteoritic iron, Meteorttics, 8, 189-196, 1973.

Baldanza, B., and G. Pialla, Dynamically deformed structures in some meteorites, in Meteorite Research, edited by P.M. Millman, pp. 806-825, D. Reidel, Hingham, Mass., 1969.

Barucci, M.A., M. Fulchignoni, and R. Salvatori, Asteroid photometry simulated in the laboratory: Phase functions of some meteorites used as irregular asteroid models (abstract), Lunar Planet. Scl. Conf., XV, 35-36, 1984.

Bell, J.F., Mineralogical evolution of meteorite parent bodies (abstract), Lunar Planet. Scl. Conf., XVII, 985-986, 1986.

Bell, J.F., and K. Keil, Spectral alteration effects in chondritic gas-rich breccias: Implications for S-class and Q-class asteroids (abstract), Lunar Planet. Sct. Conf., XVIII, 58-59, 1987.

Bell, J.F., M.J. Gaffey, and B.R. Hawke, Spectroscopic identification of probable pallasite parent bodies (abstract), Meteoritlcs, 19, 187-188, $1984 a$.

Bell, J.F., B.R. Hawke, and M.J. Gaffey, The olivine asteroids: discovery, mineralogy, and relationship to meteorites (abstract), Lunar Planet. Scl. Conf., XV, 48-49, $1984 b$.

Bell, J.F., P.D. Owensby, B.R. Hawke, and M.J. Gaffey, The 52-color asteroid survey: Final results and interpretation (abstract), Lunar Planet. Scl. Conf., XIX, 57-58, 1988.

Blodgett Jr., A.J., and W.E. Spicer, Experimental determination of the optical density states of iron, Phys. Rev., 158, 514-523, 1967.

Britt, D.T., and C.M. Pieters, The optical effects of small-scale surface processes on small bodies (abstract), Meteorttics, 22, 340-342, 1987.

Britt, D.T., and C.M. Pieters, Bidirectional reflectance properties of iron-nickel meteorites, Proc. Lunar Planet. Sci. Conf., 18th, 503-512, 1988.

Buchwald, V.F., Handbook of Iron Meteorttes, University of California Press, Berkeley, 1975.

Burns, R.G., Crystal field spectra and evidence of cation ordering in olivine minerals, Am. Mineral., 55, 1608-1632, $1970 a$

Burns, R.G., Mineralogical Applications of Crystal Field Theory, Cambridge University Press, New York, $1970 b$.

Burns, R.G., F.E. Huggins, and R.M. Abu-Eid, Polarized absorption spectra of single crystals of lunar pyroxenes and olivines, Moon, 4, 93-102, 1972.

Burns, R.G., D.J. Vaughan, R.M. Abu-Eid, and M. Witner, Spectral evidence for $\mathrm{Cr}^{3+}, \mathrm{Ti}^{3+}$, and $\mathrm{Fe}^{2+}$ rather than $\mathrm{Cr}^{2+}$ and $\mathrm{Fe}^{3+}$ in lunar ferromagnesian silicates, Proc. Lunar Sci. Conf., 4th, 983-994, 1973.

Buseck, P.R., Pallasite meteorites-Mineralogy, petrology and geochemistry, Geochim. Cosmochim. Acte, 41, 711-740, 1977.

Chapman, C.R., and M.J. Gaffey, Reflectance spectra for 277 asteroids, in Asterolds, edited by T. Gehrels, pp. 655-687, University of Arizona Press, Tucson, 1979.

Chapman, C.R., and J.W. Salisbury, Comparisons of meteorite and asteroid spectral reflectivities, Icarus, 19, 507-522, 1973.

Cintala, M.J., J.W. Head, and L. Wilson, The nature and effects of impact cratering on small bodies, in Asterolds, edited by T. Gehrels, pp. 579-600, University of Arizona Press, Tucson, 1979.

Clark, R.N., A large-scale interactive one dimensional array processing system, Publ. Astron. Soc. Pac., 92, 221-224, 1980.

Clark, R.N., Spectral properties of mixtures of montmorillonite and dark carbon grains: Implications for remote sensing minerals containing chemically and physically adsorbed water, J. Geophys. Res., 88, 10,635-10,644, 1983.

Clark, S.P., Jr., Absorption spectra of some silicates in the visible and near infrared, Am. Mineral., 42, 732-742, 1957.

Cloutis, E.A.. Interpretive techniques for reflectance spectra of mafic silicates, M.Sc. thesis, Univ. of Hawaii, Honolulu, 1985.

Cloutis, E.A., Olivine-metal mixtures: Spectral reflectance properties and phase determinations (abstract), Lunar Planet. Scl. Conf., XX, 173-174, 1989.

Cloutis, E.A., M.J. Gaffey, R. St J. Lambert, and D.G.W. Smith, The quality of geological information derivable from high resolution reflectance spectra: Results for mafic silicates, Proc. Can. Symp. Remote Sens., 10th, 309-318, $1986 a$.

Cloutis, E.A., M.J. Gaffey, T.L. Jackowski, and K.L. Reed, Calibrations of phase abundance, composition, and particle size distribution for olivine-orthopyroxene mixtures from reflectance spectra, J. Geophys. Res.. 91, 11,641-11,653, $1986 b$.

Cloutis, E.A., M.J. Gaffey, D.G.W. Smith, and R. St J. Lambert, Reflectance spectra of "featureless" materials and the surface mineral assemblages of $M$ and $E$ class asteroids, J. Geophys. Res., 95, 281-293, 1990.

Comerford, M.F., Comparative erosion rates of stone and iron meteorites under small-particle bombardment, Geochim. Cosmochim. Acta, 31, 1457-1471, 1967.

Comerford, M.F., Phosphide and carbide inclusions in iron meteorites, in Meteortte Research, edited by P.M. Millman, pp. 780-794, D. Reidel, Hingham, Mass., 1969.

Cruikshank, D.P., and W.K. Hartmann, The meteorite-asteroid connection: Two olivine-rich asteroids, Sclence, 223, 281-283, 1984. 
Doan, A.S., Jr., and J.I. Goldstein, The formation of phosphides in iron meteorites, in Meteortte Research, edited by P.M. Millman, pp. 763-779, D. Reidel, Hingham, Mass., 1969.

Dodd, R.T., Accretion of the ordinary chondrites, Earth Planet. Scl. Lett., 30, 281-291, 1976.

Dodd, R.T., Meteorites, A Petrologic-Chemical Synthests, Cambridge University Press, New York, 1981.

Dollfus, A., and B. Zellner, Optical polarimetry of asteroids and laboratory samples, in Asterolds, edited by T. Gehrels, pp. 170-183, University of Arizona Press, Tucson, 1979.

Dolifus, A., J.-C. Mandeville, and M. Duseaux, The nature of the M-type asteroids from optical polarimetry, Icarus, 37, 124-132, 1979.

Dollfus, A., A. Cailleux, B. Cervelle, C.T. Hua, and J.-C. Mandeville, Reflectance spectrophotometry extended to u.v. for terrestrial, lunar and meteoritic samples, Geochim. Cosmochim. Acta, 44, 1293-1310, 1980.

Easton, A.J., Grain-size distribution and morphology of metal in E-chondrites, Meteorttics, 18, 19-27, 1983.

Feierberg, M.A., H.P. Larson, and C.R. Chapman, Spectroscopic evidence for undifferentiated S-type asteroids, Astrophys. J., 257, 361-372, 1982.

Gaffey, M.J., Spectral reflectance characteristics of the meteorite classes, J. Geophys. Res., 81, 905-920, 1976.

Gaffey, M.J., Rotational spectral variations of asteroid (8) Flora: Implications for the nature of the S-type asteroids and for the parent bodies of the ordinary chondrites, Icarus, 60 , 83-114, 1984.

Gaffey, M.J., The spectral and physical properties of metal in meteorite assemblages: Implications for asteroid surface materials, Icarus, 66, 468-486, 1986.

Gaffey, M.J., Thermal history of the asteroid belt: Implications for accretion of the terrestrial planets (abstract), Lunar Planet. Sci. Conf., XIX, 369-370, 1988.

Gaffey, M.J., The abundance of metal on S-asteroid surfaces: Indications from IRAS 12 and 25 micron flux ratios (abstract), Lunar Plenet. Scl. Conf., XX, 321-322, 1989.

Gaffey, M.J., J.F. Bell, and D.P. Cruikshank, Reflectance spectroscopy and asteroid surface mineralogy, papers presented at Asteroids II. Univ. of Ariz., Tucson, March 8, 1988.

Geake, J.E., and A. Dollfus, Planetary surface texture and albedo from parameter plots of optical polarization data, Mon. Not. R. Astron. Soc., 218, 75-91, 1986.

Gorban, N.Y., and V.S. Stashchuk, Optical absorption of $\mathrm{Ni}-\mathrm{Fe}$ alloys, Opt. Spectrosc., 37, 202-203, 1974.

Gorban, N.Y., V.S. Stashchuk, A.V. Shirin, and A.A. Shishlovskii, Optical properties of nickel-iron alloys in the region of interband transitions, Opt. Spectrosc., 35, 295-298, 1973.

Gradie, J., and E. Tedesco, Compositional structure of the asteroid belt, Sclence, 216, 1405-1407, 1982.

Hapke, B., Bidirectional reflectance spectroscopy, 1 , Theory, $J$. Geophys. Res., 86, 3039-3054, 1981.

Hazen, R.M., H.K. Mao, and P.M. Bell, Effects of compositional variation on absorption spectra of lunar olivines, Proc. Lunar Sct. Conf., 8th, 1081-1090, 1977.

Hiroi, T., M. Miyamoto, and Y. Takano, An assignment of photon absorptions to $\mathrm{Fe}^{2+}$ and $\mathrm{Cr}_{\mathrm{r}}^{3+}$ in pyroxenes and olivine by crystal field theory (abstract), Lunar Planet. Scl. Conf. XVI, 356-357, 1985

Housen, K.R., and L.L. Wilkening, Regoliths on small bodies in the solas system, Annu. Rey. Earth Planet. Scl., 10, $355-376,1982$.

Housen, K.R., L.L. Wilkening, C.R. Chapman, and $\mathbf{R}$ Greenberg, Asteroidal regoliths, Icarus, 39, 317-351, 1979a.

Housen, K.R., L.L. Wilkening, C.R. Chapman, and R.J. Greenberg, Regolith development and evolution on asteroids and the Moon, in Asteroids, edited by T. Gehrels, pp. 601-627, University of Arizona Press, Tucson, $1979 b$.

Hunt, G.R., and R.C. Evarts, The use of near-infrared spectroscopy to determine the degree of serpentinization of ultramafic rocks, Geophysics, 46, 316-321, 1981.

Hunt, G.R., and J.W. Salisbury, Visible and near-inf rared spectra of minerals and rocks, I, Silicate minerals, Mod. Geol., 1, 283-300, 1970.
Johnson, T.V., and F.P. Fanale, Optical properties of carbonaceous chondrites and their relationship to asteroids, $J$. Geophys. Res., 78, 8507-8518, 1973.

Keil, K., Mineralogical and chemical relationships among enstatite chondrites, J. Geophys. Res., 73, 6945-6976, 1968.

King, E.A., E. Jarosewich, and F.W. Daugherty, Tierra Blanca: An unusual achondrite from west Texas, Meteoritics, 16, 229-237, 1981.

King, T.V.V., and W.I. Ridley, Relation of the spectroscopic reflectance of olivine to mineral chemistry and some remote sensing implications, J. Geophys. Res., 92, 11,457-11,469, 1987.

King, T.V.V., M.J. Gaffey, and L.A. McFadden, Evidence for regolith maturation on asteroids (abstract), Lunar Planet. Sct. Conf., XV, 429-430, 1984.

Mao, H.K., and P.M. Bell, Interpretation of the pressure ef fect on the optical absorption bands of natural fayalite to 20 $\mathrm{kb}$, Year Book Carnegie Inst. Washington, 71, 524-527, 1972.

Marcus, H.L., and L.H. Hackett Jr., The low temperature fracture behavior of iron-nickel meteorites, Meteoritics, 9, 371-376, 1974.

Mason, B., Meteorttes, John Wiley, New York, 1962.

Mason, B., The enstatite chondrites, Geochlm. Cosmochlm. Acta, 30, 23-39, 1966.

Mason, B., and E. Jarosewich, The Barea, Dyarrl Island, and Emery meteorites, and a review of the mesosiderites, Mineral. Mag., 39, 204-215, 1973.

Matsui, T., and P.H. Schultz, On the brittle-ductile behavior of iron meteorites: New experimental constraints, Proc. Lunar Planet. Scl. Conf., 15th, Part 1, J. Geophys. Res. 89, suppl., C323-C328, 1984.

McFadden, L.A., Spectral reflectance of near-earth asteroids: Implications fot composition, origin and evolution, Ph.D. thesis, Univ. of Hawaii, Honolulu, 1983.

McFadden, L.A., M.J. Gaffey, H. Takeda, T.L. Jackowski, and K.L. Reed, Reflectance spectroscopy of diogenite meteorite types from Antarctica and their relationship to asteroids, Proceedings of Seventh Symposium on Antarctic Meteorites, Mem. Natl. Inst. Polar Res. Spec. Issue, 25, 188-206, 1982.

Miyamoto, M., Diffuse reflectance from $0.25 \mu \mathrm{m}$ to $25 \mu \mathrm{m}$ of the Yamato-691 enstatite chondrite, Proceedings of Eleventh Symposium on Antarctic Meteorites, Mem. Natl. Inst. Polar Res. Spec. Issue, 46, 123-130, 1987.

Miyamoto, M.. A. Mito, Y. Takano, and N, Fujii, Spectral reflectance $(0.25-2.5 \mu \mathrm{m})$ of powdered olivines and meteor ites, and their bearing on surface materials of asteroids, Proceedings of Sixth Symposium on Antarctic Meteorites, Mem. Natl. Inst. Polar Res. Spec. Issue, 20, 345-361, 1981.

Miyamoto, M., M. Kinoshita, and $Y$. Takano, Spectral reflectance $(0.25-2.5 \mu \mathrm{m})$ of olivine and pyroxene from an ordinary chondrite, Proceedings of Eighth Symposium on Antarctic Meteorites, Mem. Nall. Inst. Polar Res. Spec. Issue, 30, 367-377, 1983.

Moore, C.B., and C.F. Lewis, Total carbon content in ordinary chondrites, J. Geophys. Res., 72, 6289-6292, 1967.

Mori, H., H. Takeda, M. Prinz, and G.E. Harlow, Mineralogical and crystallographic studies of lodranite and primitive achondrite groups bearing on their genetic link (abstract), Lunar Planet. Sci. Conf., XV, 567-568, 1984.

Morrison, D., and L. Lebofsky, Radiometry of asteroids, in Asteroids, edited by $T$. Gehrels, pp. 184-205, University of Arizona Press, Tucson, 1979.

Morrison, B., and B. Zellner, Polarimetry and radiometry of the asteroids, in Asterolds, edited by $T$. Gehrels, pp. 1090-1097, University of Arizona Press, Tucson, 1979.

Mustard, J.F., C.M. Pieters, and S.F. Pratt, Deconvolution of spectra for intimate mixtures (abstract), Lunar Planet. Scl. Conf., XVII, 593-594, 1986.

Nagahara, H., and K. Ozawa, Petrology of Yamato-791493 "lodranite": Melting, crystallization, cooling history, and relationship to other meteorites, Proceedings of Tenth Symposium on Antarctic Meteorites, Mem. Natl. Inst. Polar Res. Spec. Issue, 41, 181-205, 1986.

Nash, D.B., and J.E. Conel, Spectral reflectance systematics 
for mixtures of powdered hypersthene, labradorite, and ilmenite, J. Geophys. Res., 79, 1615-1621, 1974.

Ostro, S.J., D.B. Campbell, and 1.1. Shapiro, Main belt asteroids: Dual-polarization radar observations, Science, 229. 442-446, 1985

Papike, J.J., F.N. Hodges, A.E. Bence, M. Cameron, and J.M. Rhodes, Mare basalts: Crystal chemistry, mineralogy, and petrology, Rev. Geophys., 14, 475-540, 1976.

Pieters, C.M., Polarization in a mineral absorption band, in Planets, Stars and Nebulae Studied with Photopolarlmetry, edited by T. Gehrels, pp. 405-418, University of Arizona Press, Tucson, 1974.

Pieters, C.M., Strength of mineral absorption features in the transmitted component of near-infrared light: First results from RELAB, J. Geophys. Res., 88, 9534-9544, 1983.

Pieters, C.M., and J.F. Mustard, Exploration of crustal/mantle material for the Earth and Moon using reflectance spectroscopy, Remote Sens. Environ., 24, 151-178, 1988.

Powell, B.N., Petrology and chemistry of mesosiderites, I, Textures and composition of nickel-iron, Geochlm. Cosmochlm. Acta, 33, 789-810, 1969.

Powell, B.N., Petrology and chemistry of mesosiderites, II, Silicate textures and compositions and metal silicate relationships, Geochim. Cosmochim. Acta, 35, 5-34, 1971.

Prinz, M., D.G. Waggoner, and P.J. Hamilton, Winonaites: A primitive achondrite group related to silicate inclusions in IAB irons (abstract), Lunar Planet. Scl. Conf., XI, 902-904, 1980.

Remo, J.L., and A.A. Johnson, A preliminary study of the ductile-brittle transition under impact conditions in material from an octahedrite, J. Geophys. Res., 80, 3744-3748, 1975.

Robinson, P., The compositional space of terrestrial pyroxenes, Rey. Mineral., 7, Pyroxenes, edited by C.T. Prewitt, 419-494, 1980.

Roush, T.L., Effects of temperature on remotely sensed mafic mineral absorption features, M.Sc. thesis, Univ. of Hawaii, Honolulu, 1984.

Runciman, W.A., D. Sengupta, and J.T. Gourley, The polarized spectra of iron in silicates, II, Olivine, Am. Mineral., 58, 451-456, 1973.

Salisbury, J.W., G.R. Hunt, and C.J. Lenhoff, Visible and near-infrared spectra, X, Stony meteorites, Mod. Geol., 5 , $115-126,1975$

Singer, R.B., Near-infrared spectral reflectance of mineral mixtures: Systematic combinations of pyroxenes, olivine, and iron oxides, J. Geophys. Res., 86, 7967-7982, 1981.

Veeder, G.J., D.L. Matson, and J.C. Smith, Visual and infrared photometry of asteroids, Astron. J., 83, 651-663, 1978.

Veeder, G.J., D.L. Matson, and E.F. Tedesco, The R asteroids reconsidered, Icarus, 55, 177-180, 1983.

Veverka, J., Photopolarimetric observations of the minor planet Flora, Icarus, 15, 454-458, 1971.
Veverka, J., Photopolarimetric observations of 9 Metis, 15 Eunomia, 89 Julia, and other asteroids, Icarus, 19, 114-117, 1973.

Wagner, J.K., B.W. Hapke, and E.N. Wells, Atlas of reflectance spectra of terrestrial, lunar, and meteoritic powders and frosts from 92 to $1800 \mathrm{~nm}$, Icarus, 69, 14-28, 1987.

Watson, F.G., Reflectivity and color of meteorites, Proc. Natl. Acad. Scl. U.S.A., 24, 532-537, 1938.

Watters, T.R., and M. Prinz, Aubrites: Their origin and relationship to enstatite chondrites, Proc. Lunar Planet. Sct. Conf., 10ih, 1073-1093, 1979.

Weidner, V.R., and J.J. Hsia, Reflection properties of pressed polytetrafluoroethylene powder, J. Opt. Soc. Am., 71, 856-861, 1981.

White, W.B., and K.L. Keester, Selection rules and assignments for the spectra of ferrous iron in pyroxenes, Am. Mineral., 52, 1508-1514, 1967.

Wilkening, L.L.. What meteorites can tell us about regoliths (abstract), Meteorttics, 18, 421-422, 1983.

Williams, C.V., K. Keil, A.E. Rubin, and A. San Miguel, Petrology of some ordinary chondrite regolith breccias: Implications for parent body history (abstract), Meteorttics, 19, 338, 1984.

Williams, C.V., E.R.D. Scott, G.J. Taylor, K. Keil, L. Schultz, and $\mathrm{R}$. Wieler, Histories of ordinary chondrite parent bodies: Clues from regolith breccias (abstract), Meteoritics, 21, 541, 1986.

Yanai, K., and H. Kojima, A new stony-iron meteorite collection in the Yamato meteorites (abstract), Meteoritics, 18, 429, 1983.

Yolken, H.T., and J. Kruger, Optical constants of iron in the visible region, J. Opt. Soc. Am., 55, 842-844, 1965.

Zellner, B., M. Leake, T. Lebertre, M. Duseaux, and A. Dollfus, The asteroid albedo scale, I, Laboratory polarimetry of meteorites, Proc. Lunar Planet. Scl. Conf., 8th, 1091-1110, 1977.

Zukas, E.G., Metallurgical results from shock-loaded iron alloys applied to a meteorite, J. Geophys. Res., 74, 1993-2001, 1969.

E.A. Cloutis, R. St J. Lambert, and D.G.W. Smith, Department of Geology, University of Alberta, Edmonton, Alberta, Canada T6G 2E3.

M.J. Gaffey, Department of Geology, West Hall, Rensselaer Polytechnic Institute, Troy, NY 12181.

(Received March 31, 1989;

revised July 31, 1989;

accepted November 2, 1989.) 